\title{
Effects of Tamiflu and Adamine on histology and ultrastructure of the liver of albino mice
}

\author{
Nagla Zaky Ibrahim El-Alfy, Samia Mohamed Sakr, Mahmoud Fathy Mahmoud and Heba Ahmed Omar
}

\begin{abstract}
Background: Tamiflu (Oseltamivir) and Adamine (Amantadine $\mathrm{HCl}$ ) are antiviral drugs which are used for prevention and treatment for influenza. The present study was carried out to evaluate the effect of Tamiflu and Adamine on the liver of adult male albino mice from the histological and ultrastructural points of views.

Results: Histological examination of liver sections treated with Tamiflu and Adamine included enlargement and congestion of central and hepatic veins in addition to erosion of their endothelial lining cells, cytoplasmic vacuolation of hepatocytes, pyknosis of their nuclei, and dilatation of hepatic sinusoid. The electron microscopic investigation illustrated mitochondrial swelling, fragmented rough endoplasmic reticulum, cytoplasmic vacuolation, the nuclei with irregular envelope and condensed heterochromatin, dilated microvilli in sinusoid, in addition to active Kupffer cells have many lysosomes and filopodia in its membrane.

Conclusion: The study suggested that both drugs induced histopathological and ultrastructural alterations in hepatic tissue. In conclusion, Tamiflu and Adamine have pathological effects on liver of albino mice (Mus musculus).
\end{abstract}

Keywords: Adamine, Histopathology, Liver, Mice, Tamiflu ultrastructure

\section{Background}

Two classes of antiviral agents approved for the prevention of and treatment for influenza: the M2 inhibitors (amantadine and rimantadine) and the neuraminidase inhibitors (oseltamivir, laninamivir, peramivir, and zanamivir). These agents have been proven to be safe and effective alone or in combination for the treatment of uncomplicated influenza in otherwise healthy individuals [16].

The study that has been published by Burger et al. [3] indicated that treatment of mice with $100 \mathrm{mg} / \mathrm{kg} /$ day of oseltamivir twice daily for 5 days beginning $16 \mathrm{~h}$ previrus exposure does not adversely affect the primary in vivo cellular immune responses to influenza virus infection due to determination of splenic $\mathrm{T}, \mathrm{T}$-helper, $\mathrm{T}$ cytotoxic, and B lymphocytes as well as macrophages in treated and untreated mice using flow cytometry.

* Correspondence: heba_ahmed_010@hotmail.com

Biological and Geological Sciences Department, Faculty of Education, Ain Shams University, Cairo, Egypt
However, omega-hydroxylated products of oseltamivir were produced by rat liver microsomes. Sweeny et al. [30] observed both the (R)- and (S)-omega-hydroxylated products, but formation of the (R)-isomer predominated. These data indicated that in the rat, oseltamivir was primarily metabolized to the active influenza neuraminidase inhibitor GS4071 and, to a lesser extent, to an (R)omega-carboxylic acid metabolite.

Dutkowski et al. [6] studies confirmed that transient gastrointestinal disturbance is the major adverse effect of oseltamivir and that this can be reduced by taking oseltamivir after a light snack. However, a clear association between the skin reactions and oseltamivir has not been established. A large study of insurance records, which permitted the assessment of the relative risk of medical events treated in the month following prescription of oseltamivir in general use, showed no evidence of increased risk of cardiac, neuropsychiatric or respiratory

(c) The Author(s). 2021 Open Access This article is licensed under a Creative Commons Attribution 4.0 International License, which permits use, sharing, adaptation, distribution and reproduction in any medium or format, as long as you give appropriate credit to the original author(s) and the source, provide a link to the Creative Commons licence, and indicate if changes were made. The images or other third party material in this article are included in the article's Creative Commons licence, unless indicated otherwise in a credit line to the material. If material is not included in the article's Creative Commons licence and your intended use is not permitted by statutory regulation or exceeds the permitted use, you will need to obtain permission directly from the copyright holder. To view a copy of this licence, visit http://creativecommons.org/licenses/by/4.0/. 
events for those receiving oseltamivir compared with those who did not.

Although amantadine has a lower acquisition cost than oseltamivir, it is associated with more adverse events, lower efficacy, and individualized dosing requirements, leading to higher overall costs and more influenza-like illness cases than oseltamivir. Therefore, the use of oseltamivir postexposure prophylaxis is more cost-effective than the current standard of care with amantadine prophylaxis or no prophylaxis [27].

Co-administration with oseltamivir had no clinically significant effect on the pharmacokinetics of amantadine. Similarly, amantadine co-administration did not affect oseltamivir pharmacokinetics or pharmacokinetics of the metabolite, oseltamivir carboxylate. In this small trial, there was no evidence of an increase in adverse events. Although many more subjects would need to be studied to rule out a synergistic increase in adverse events, the combination in this small human drug-drug interaction trial appears safe and without pharmacokinetic consequences [20].

He et al. [15] evaluated the efficacy and safety of oseltamivir $30-75 \mathrm{mg}$, twice daily 5 days in the treatment of suspected influenza in 229 children. The same authors found that oseltamivir treatment was safe with mild side effects (stomachache, diarrhea, poor appetite, vomiting).

Recently, Dogan and Karaca [5] observed few inflammatory cells in the grey and white matter of spinal cord of Sprague-Dawley rats treated with 45 $\mathrm{mg} / \mathrm{kg}$ of intraperitoneal amantadine for 7 days after spinal cord injury, whereas mild degeneration was evident in the multipolar and bipolar cells and a few glial cells with pyknotic nuclei.

Thus the aim of the present work is to examine, assess, and evaluate the possible histopathological and ultrastructural consequences which might occur in the liver cells of male albino mice treated with Tamiflu (Oseltamivir) and Adamine (Amantadine $\mathrm{HCl}$ ).

\section{Methods}

\section{Experimental animals}

The present study was carried out on the male Swiss albino mice of CD-1 (Mus musculus) with an average age of 12 weeks and body weight of $\sim 25 \mathrm{~g}$. The animals were obtained from Theodor Bilharz Research Institute (TBRI), Imbaba, Giza, Egypt.

The animals were housed in cages and fed ad libitum with a standard diet and provided with free access to water, being kept under suitable laboratory conditions during the whole period of experimentation and the healthy animals were used.

\section{The applied drugs}

Tamiflu and Adamine are available in the form of capsules for oral administration. They contain $75 \mathrm{mg}$ and $100 \mathrm{mg}$ of the active ingredients, respectively.

In the present investigation, the experiment was designed to evaluate the histopathological and ultrastructural effect of Tamiflu (150 mg/day/each adult human) and Adamine (200 mg/day/each adult human) on liver structure of adult male albino mice.

The dose of Tamiflu (0.4 mg/each mouse, equivalent to $16 \mathrm{mg} / \mathrm{kg}$ b.wt.) and the dose of Adamine $(0.5 \mathrm{mg} /$ each mouse, equivalent to $20 \mathrm{mg} / \mathrm{kg}$ b.wt.) were calculated according to the equivalent therapeutic dosages of human-mouse conversion factor by Paget and Barnes [23], and were diluted in normal saline solution $(0.9 \%$ $\mathrm{NaCl}$ ). The doses were given orally either separately or concurrently way for the desired periods 5,10 , and 15 days to experimental mice.

\section{Experimental design}

Fifty adult mice were allocated into 10 equal groups of 5 mice each. The first group served as the control group (C group), received saline solution $(0.9 \% \mathrm{NaCl})$, and the rest 9 groups divided into T5, T10, and T15 groups; which were Tamiflu-treated groups, while the other three groups A5, A10 and A15 groups were treated with Adamine. Besides, the last three groups (TA5, TA10, and TA15) were treated with Tamiflu concurrently with Adamine. All doses were given daily for 5, 10, and 15 days

At the end of the experiment, the mice were sacrificed by severing their neck blood vessels and immediately dissected.

For light microscopic examination, small pieces of the liver of control and treated animals were fixed for $24 \mathrm{~h}$ in aqueous Bouin's fixative. The specimens were then dehydrated, cleared in terpineol, and embedded in paraffin wax. Sections $5-\mu \mathrm{m}$ thick were stained with hematoxylin and eosin, microscopically examined, and photomicrographs were made as required [2].

For ultrastructural evaluation by transmission electron microscopy as described by Dykstra et al. [7], freshly excised liver were cut into very small pieces and fixed directly in cold 4 FIG (i.e., $4 \%$ formaline $+1 \%$ glutaraldehyde adjusted at $\mathrm{pH}$ 2.2) for $24 \mathrm{~h}$. Then, they were postfixed in $1 \%$ osmium tetroxide in $0.1 \mathrm{M}$ phosphate buffer ( $\mathrm{pH}$ 7.3), dehydrated in an ethanolic series culminating in $100 \%$ acetone, and infiltrated with epoxide resin. After polymerization overnight at $60{ }^{\circ} \mathrm{C}$, semi-thin sections $(0.5 \mu \mathrm{m})$ were stained with $1 \%$ toluidine blue in sodium borate and examined with the light microscope. Ultrathin sections were cut, mounted on 200 mesh copper grids, and stained with uranyl acetate and lead citrate [26]. The stained grids were examined and 
photographed by a JEOL-JEM-1400 EX- electron microscope, at the Regional Center for Mycology and Biotechnology (RCMB), Al-Azhar University.

\section{Results \\ Histological and histopathological observations Group I: the control mice}

The liver of the control mouse exhibited the common characteristic lobular organization of the mammalian liver. Each lobule is formed of cords of hepatocytes radiating from a central vein. The hepatic cords are separated from each other by blood sinusoids lined with endothelial cells interspersed by Kupffer cells (Fig. 1). The hepatic lobules are separated by loose connective tissue containing at certain angles the portal triads including branches of the portal vein, hepatic artery and a narrow bile ductule (Fig. 2).

\section{Group II: Tamiflu-treated mice}

The liver of Tamiflu-treated mice for 5, 10, and 15 days revealed mild pathological alterations in the hepatic tissues. The hepatocytes appeared vacuolated with pyknotic nuclei after 15 days of treatment. There was accumulation of inflammatory cells in the vicinity of enlarged and congested central and hepatic veins. A damage of endothelial lining of central vein was also appeared (Figs. 3, 4, and 5). These alterations were timedependent.

\section{Group III: Adamine-treated mice}

Mice treated with Adamine for 5, 10, and 15 days showed signs of moderate pathological alterations in liver tissues. These pathological alterations include cytoplasmic vacuolation and pyknotic nuclei in hepatocytes. There was accumulation of inflammatory cells in addition to enlargement and congestion of central veins in addition to damage of their endothelial lining (Figs. 6, 7, and 8). These alterations were time-dependent.

\section{Group IV: Tamiflu in addition to Adamine-treated mice}

The pathological changes in hepatic tissues of mice for 5 , 10, and 15 days with Tamiflu concurrently with Adamine showed severe histopathological changes such as appearance of pyknotic nuclei in hepatocytes. An enlargement and congestion of central and hepatic veins with damage of their endothelial lining were also seen in addition to dilatation in hepatic sinusoid (Figs. 9, 10, and 11). These alterations were time-dependent.

\section{Ultrastructural observations \\ Group I: the control mice}

The ultrastructure of the liver of control mice is shown in Fig. 12. The cytoplasmic organelles as well as the nuclei of the hepatocytes exhibited the normal ultrastructural appearance. The cytoplasm contained numerous mitochondria dispersed all over the cytoplasm. The mitochondria were spherical or ovoid in shape with

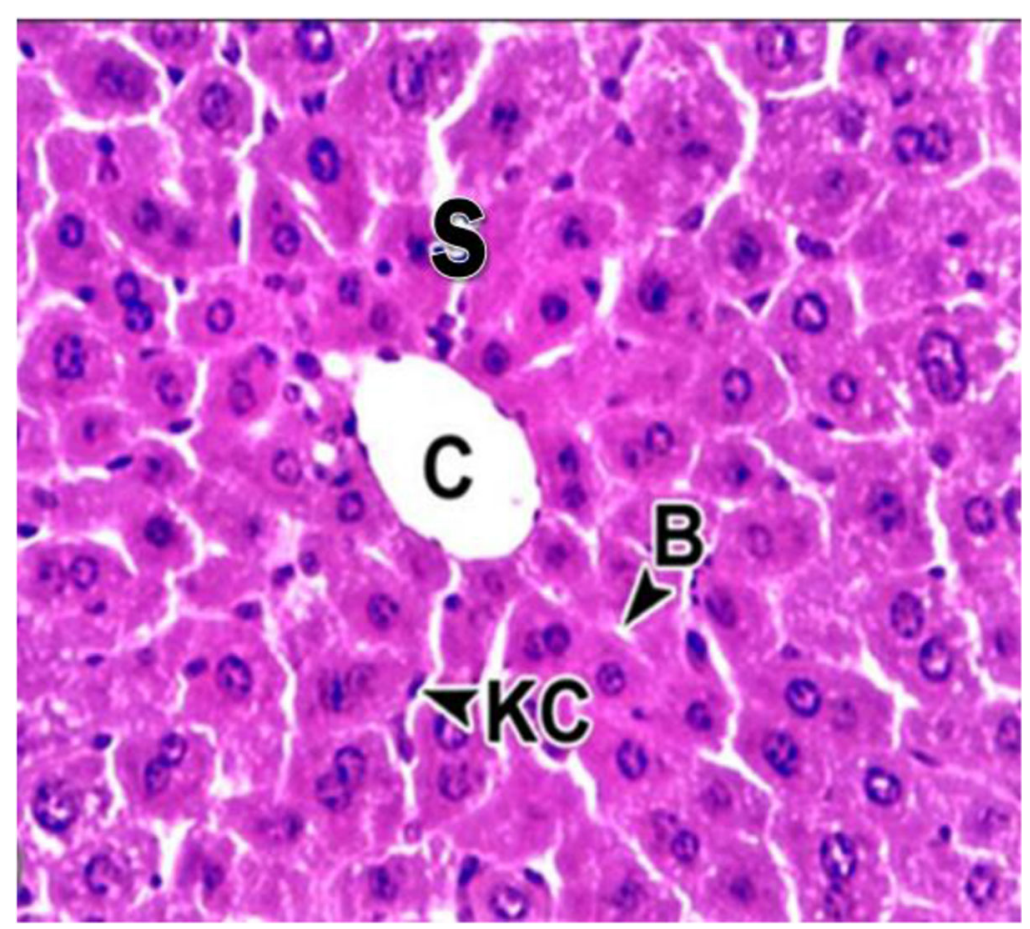

Fig. 1 Photomicrograph of a section of the liver of control mouse showing the central vein (C). Notice the blood sinusoids (S) are seen between the hepatic strands. Kupffer cells $(K C)$ intervenes the walls of the sinusoids. $(H \& E, \times 600)$ 


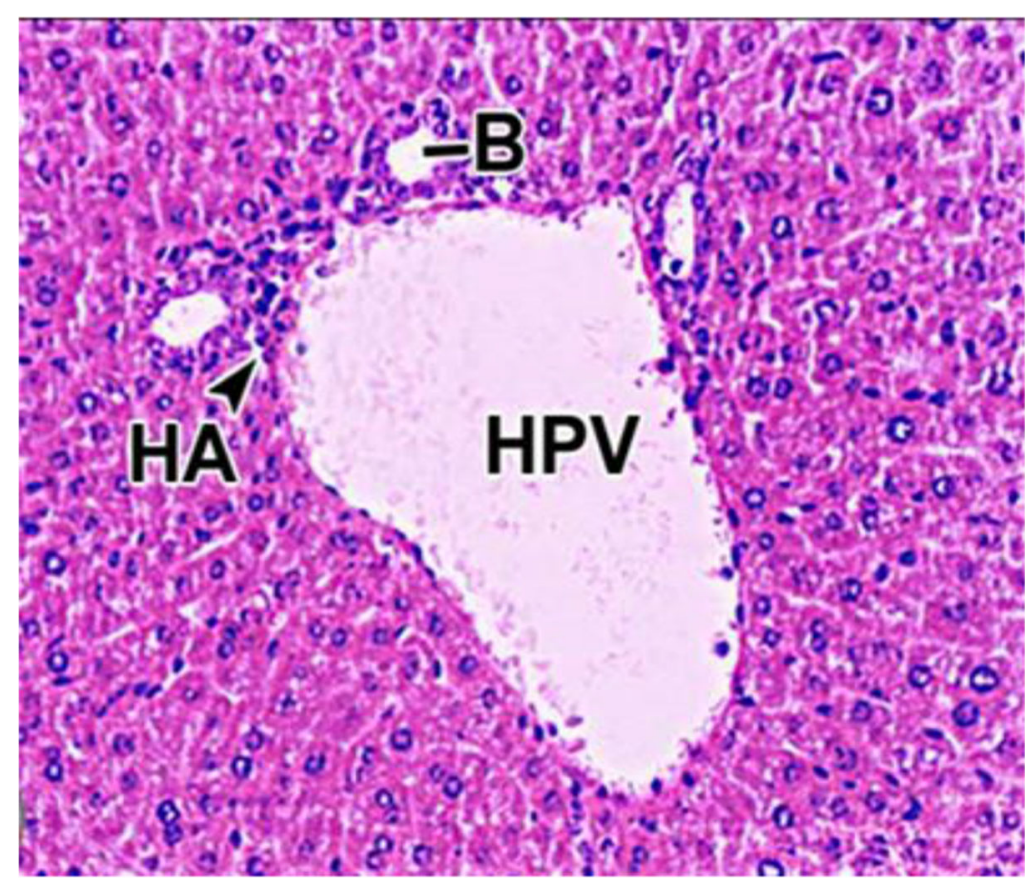

Fig. 2 Photomicrograph of a section of the liver of control mouse, showing a portal area containing a branch of the hepatic portal vein (HPV), hepatic artery (HA), and bile ductule (B). ( $H \& E, \times 400)$

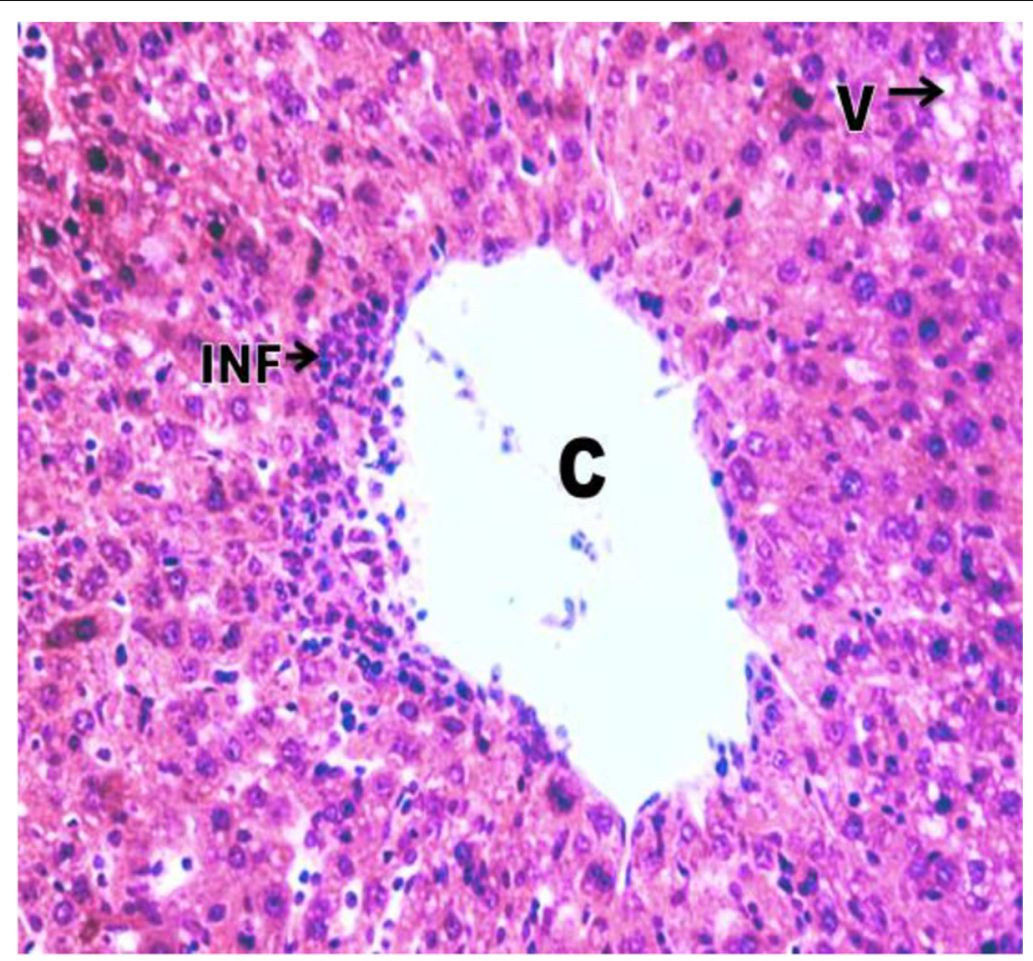

Fig. 3 Photomicrograph of a section of the liver of treated mouse with Tamiflu ( $16 \mathrm{mg} / \mathrm{kg}$ b.wt.) for 5 days showing hepatocytes with cytoplasmic vacuolation (V), inflammatory cells (INF), and damage of endothelial lining of central vein (C). (H\&E, $\times 400)$ 


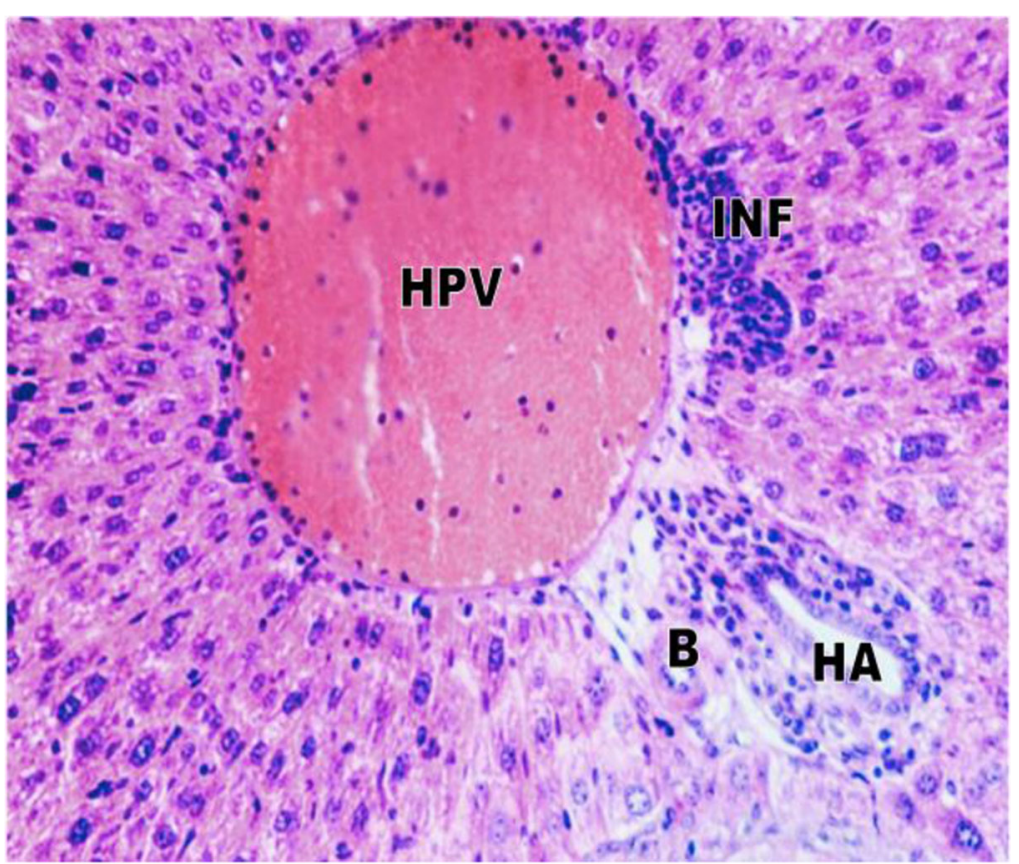

Fig. 4 Photomicrograph of a section of the liver of treated mouse with Tamiflu (16 mg/kg b.wt.) for 10 days revealing inflammatory cells (INF) in the vicinity of enlarged and congested hepatic portal vein (HPV). (H\&E, $\times 400)$

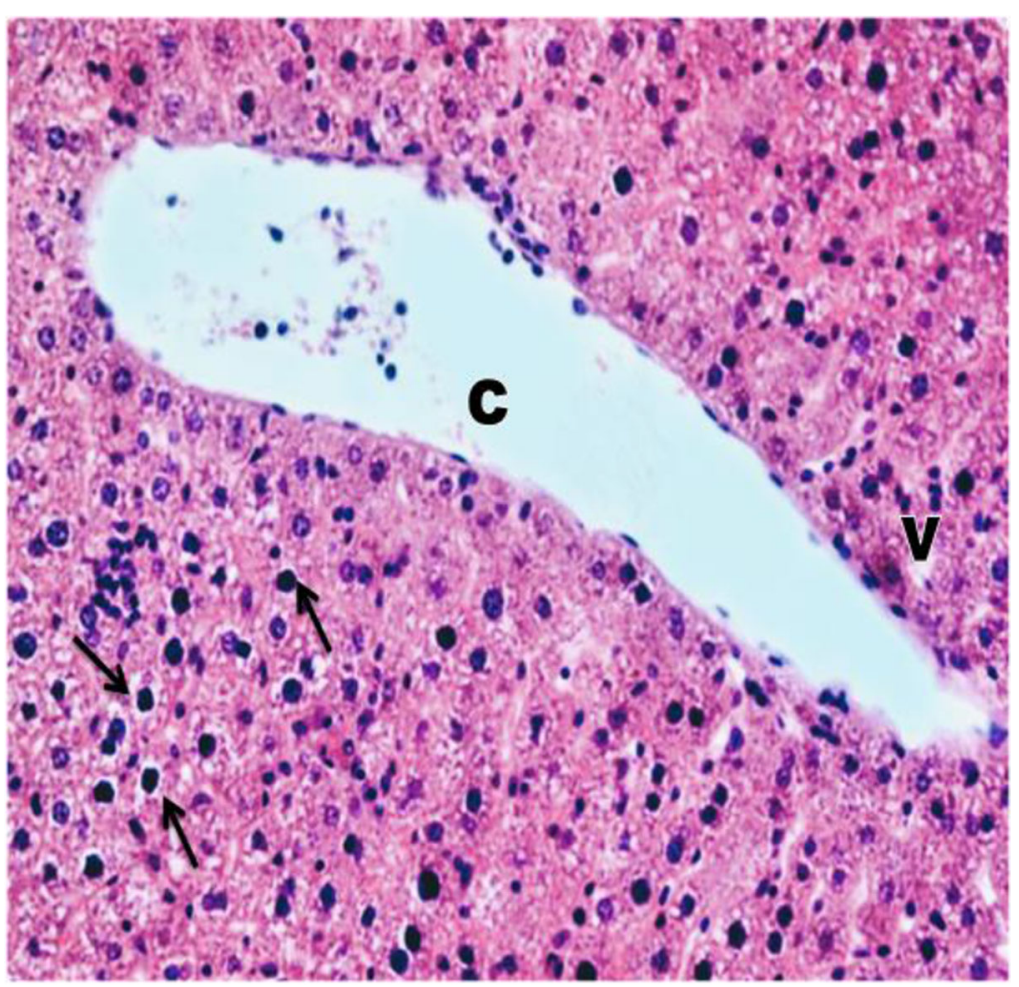

Fig. 5 Photomicrograph of a section of the liver of treated mouse with Tamiflu ( $16 \mathrm{mg} / \mathrm{kg}$ b.wt.) for 15 days revealing hepatocytes with vacuoles $(V)$ and pyknotic nuclei (arrows) in addition to enlargement and distortion of central vein (C). (H\&E, $\times 400)$ 


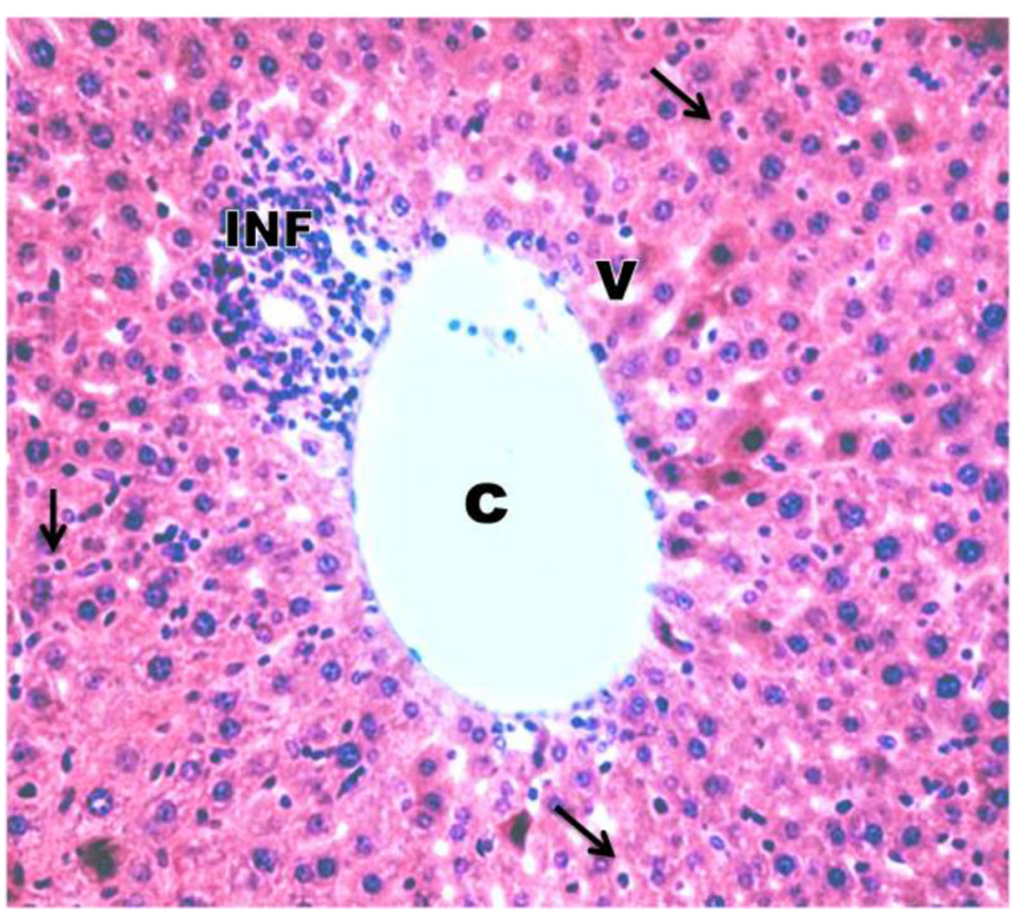

Fig. 6 Photomicrograph of a section of the liver of treated mouse with Adamine (20 mg/kg b.wt.) for 5 days revealing hepatocytes with clear vacuoles $(V)$ and pyknotic nuclei (arrows), notice accumulation of inflammatory cells (INF) in the vicinity of central vein $(C)$. (H\&E, $\times 400)$

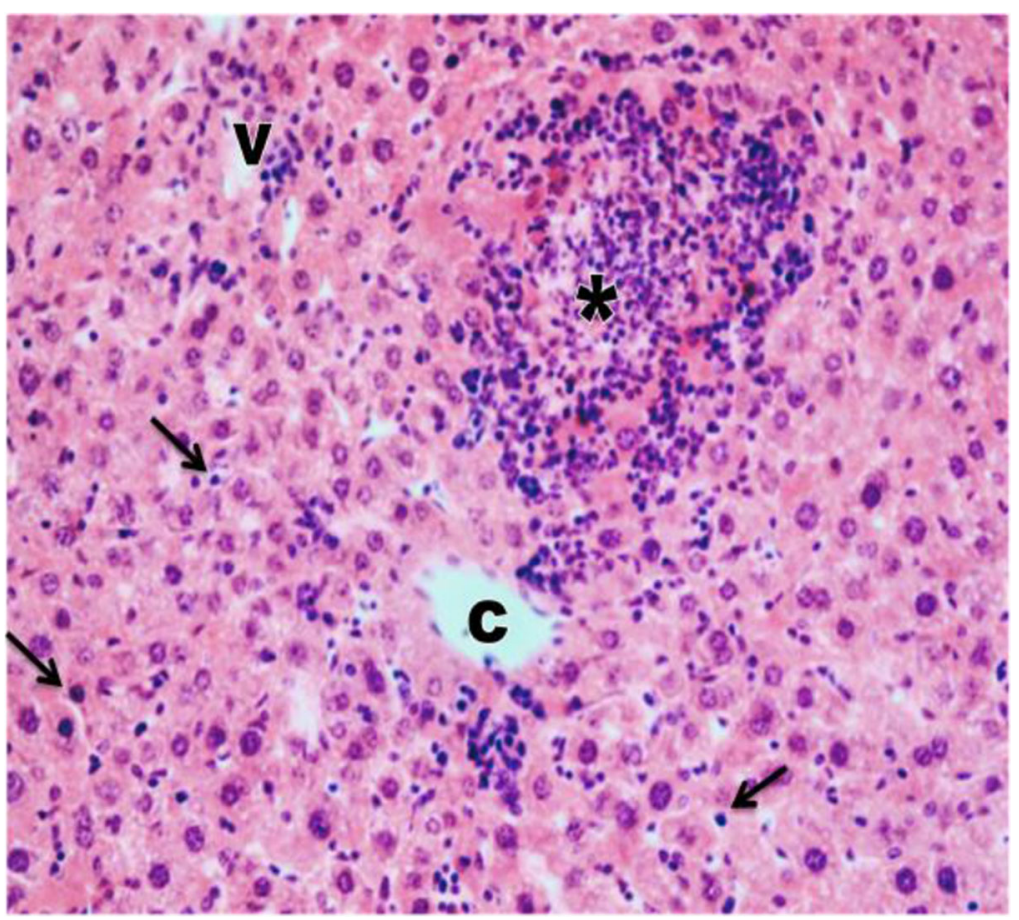

Fig. 7 Photomicrograph of a section of the liver of treated mouse with Adamine ( $20 \mathrm{mg} / \mathrm{kg}$ b.wt.) for 10 days showing hepatocytes with cytoplasmic vacuolation (V), pyknotic nuclei (arrows), and focal area of necrosis is also appear $\left.{ }^{*}\right)$. $(H \& E, \times 400)$ 


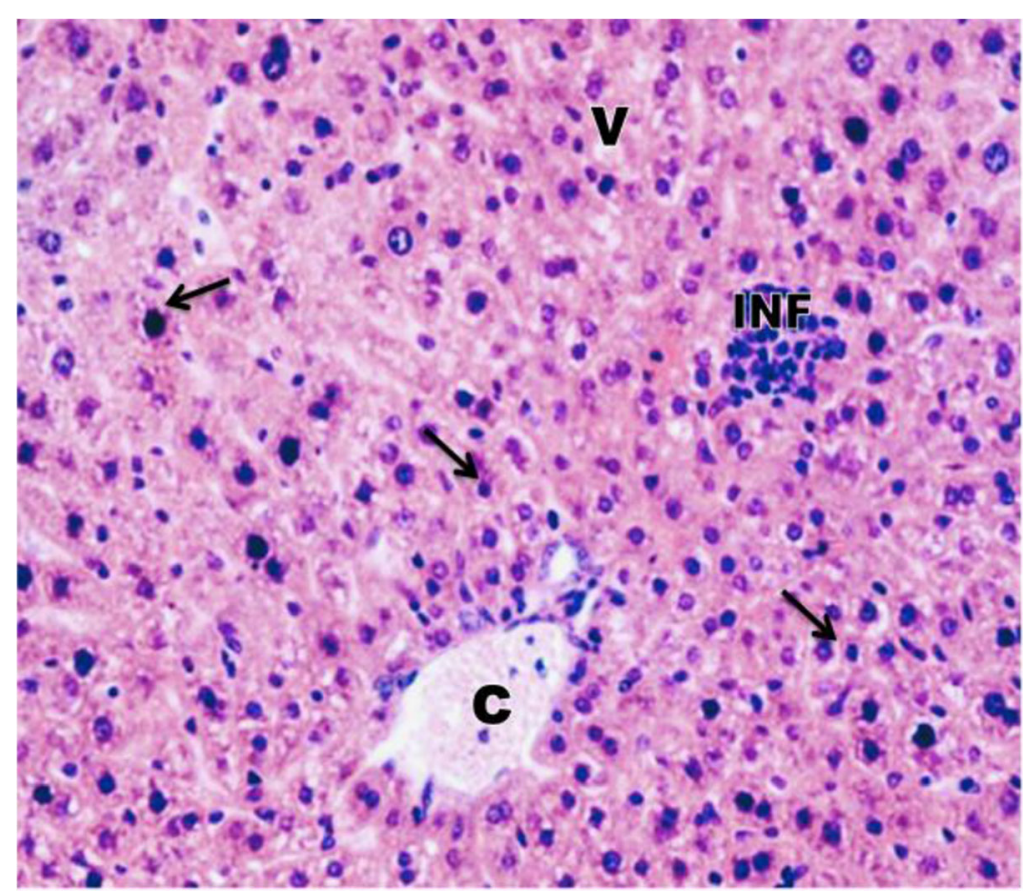

Fig. 8 Photomicrograph of a section of the liver of treated mouse with Adamine ( $20 \mathrm{mg} / \mathrm{kg}$ b.wt.) for 15 days showing vacuoles $(\mathrm{V})$ in hepatocytes with pyknotic nuclei (arrows), inflammatory cells (INF), and congestion of central vein (C). (H\&E, $\times 400)$

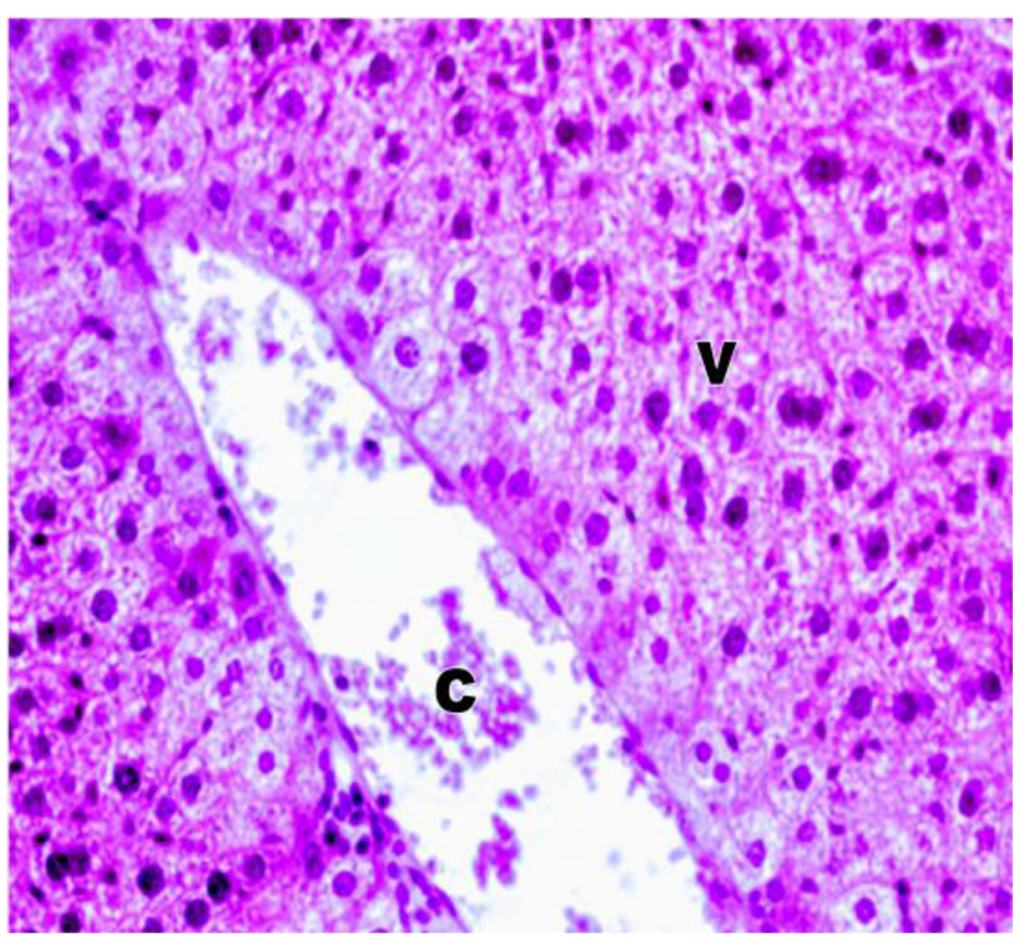

Fig. 9 Photomicrograph of a section of the liver of treated mouse with Tamiflu (16 mg/kg b.wt.) in addition to Adamine (20 mg/kg b.wt.) for 5 days revealing hepatocytes with cytoplasmic vacuolation $(V)$ and enlargement of central vein (C) containing blood cells. (H\&E, $\times 400)$ 


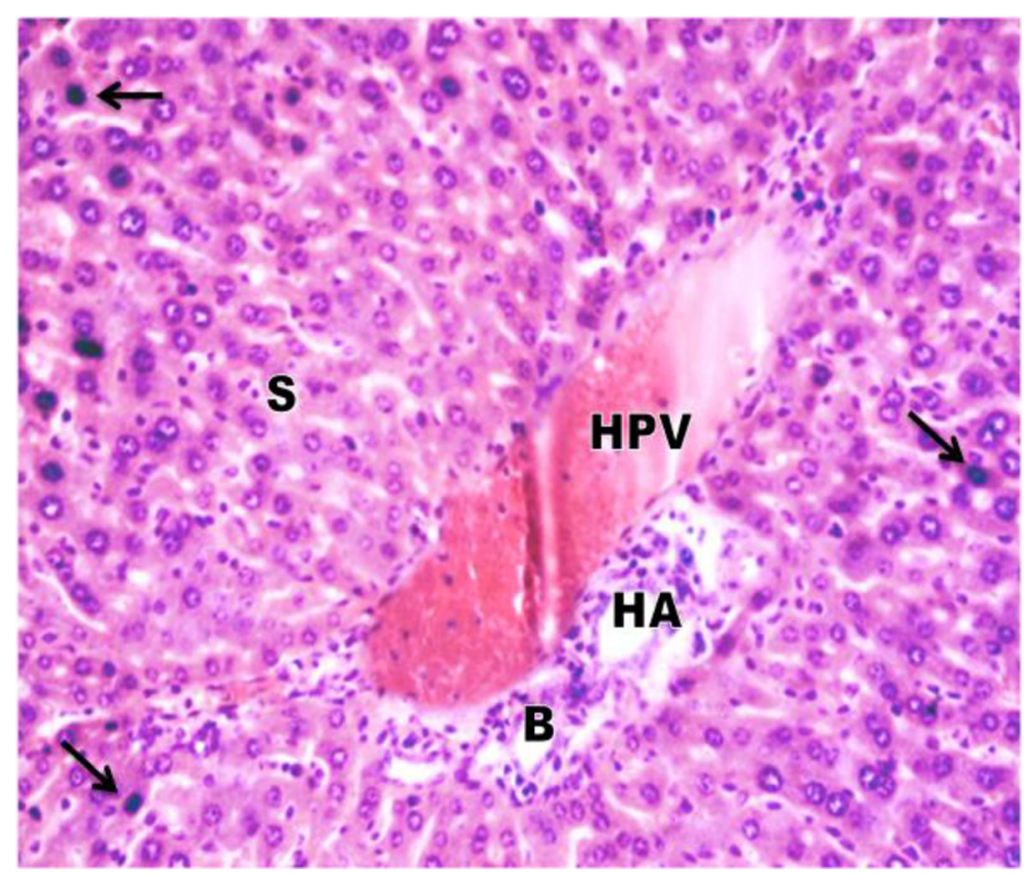

Fig. 10 Photomicrograph of a section of the liver of treated mouse with Tamiflu (16 mg/kg b.wt.) in addition to Adamine (20 mg/kg b.wt.) for 10 days revealing hepatocytes with pyknotic nuclei (arrows), enlargement, and congestion in hepatic portal vein (HPV) and dilatation of hepatic sinusoid (S). (H\&E, $\times 400)$

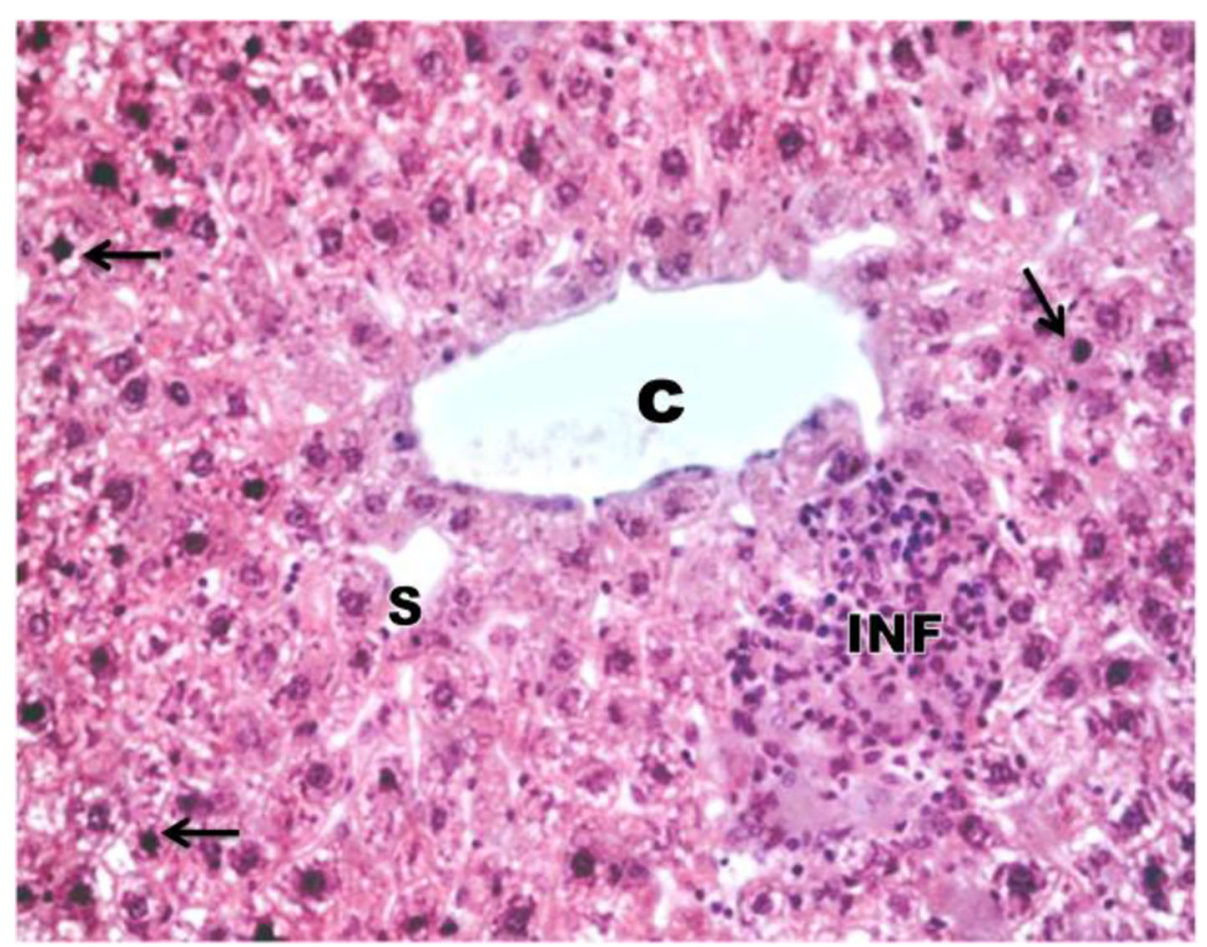

Fig. 11 Photomicrograph of a section of the liver of treated mouse with Tamiflu (16 mg/kg b.wt.) in addition to Adamine (20 mg/kg b.wt.) for 15 days showing hepatocytes with pyknotic nuclei (arrows), inflammatory cells (INF), enlargement of central vein (C), and damage of its endothelial lining and dilatation of hepatic sinusoid (S). (H\&E, $\times 400)$ 


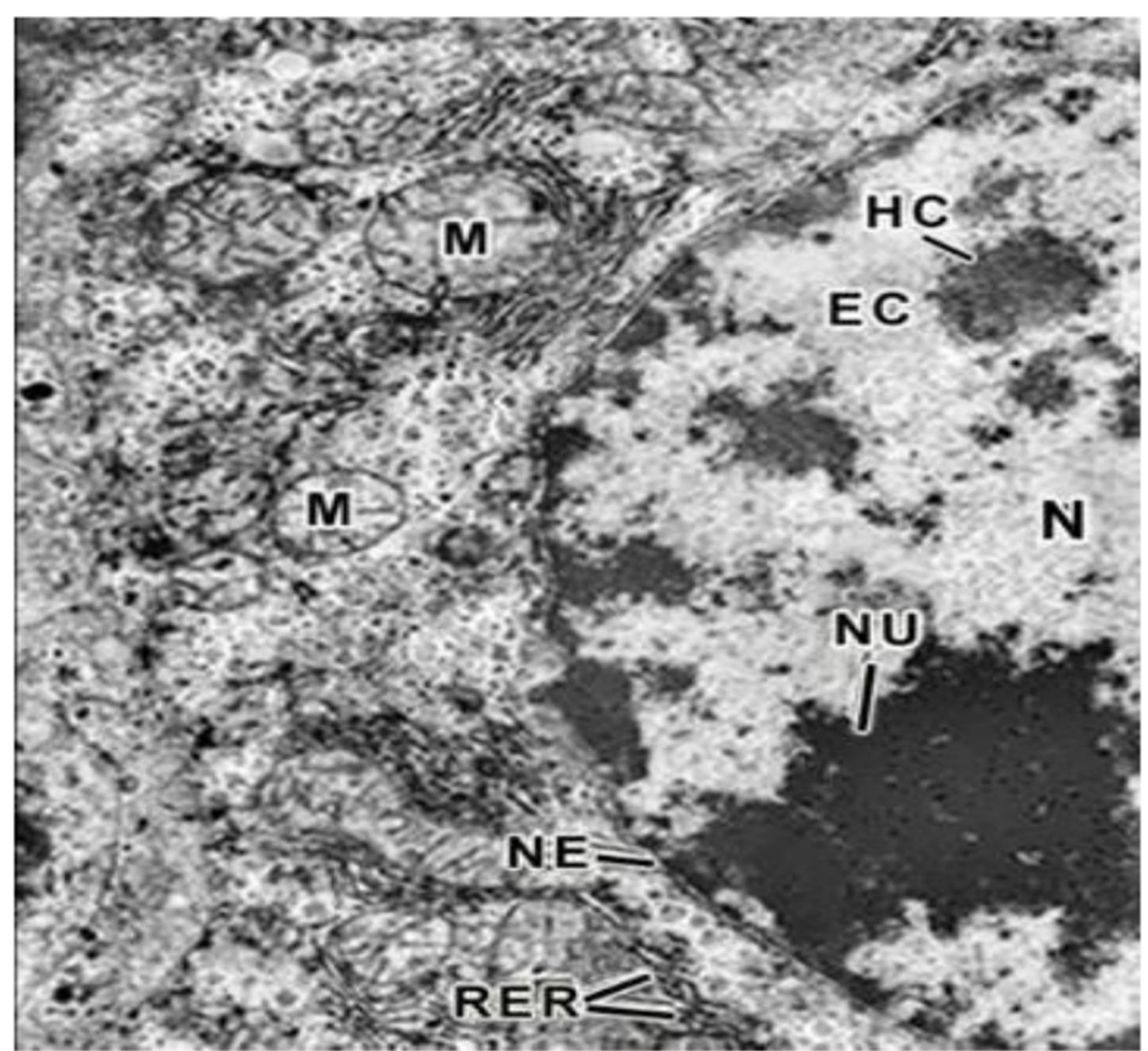

Fig. 12 An electron micrograph of a hepatocyte showing the rough endoplasmic reticulum (RER), many mitochondria (M), part of the nucleus (N) with distinct nuclear envelope (NE), well-defined nucleolus (NU), and nucleoplasm having loose euchromatin (EC) and compact heterochromatin $(\mathrm{HC})$ in normal figuring. $(\times 16,000)$

well-developed cristae. The rough endoplasmic reticulum (RER) consisted of closely packed parallel and flattened cisternae studded with ribosomes.

Considerable electron-dense glycogen rosettes or granules were clearly detected. The nucleus was spherical with a distinct nuclear envelope, and the nucleoplasm showed aggregations of euchromatin and heterochromatin materials. Hepatic sinusoid localized between the hepatocytes and lined with a Kupffer cell is observed in Fig. 13.

\section{Group II: Tamiflu-treated mice}

The ultrastructural study of the liver of mice treated with Tamiflu for 5, 10, and 15 days showed marked changes in the hepatocytes such as fragmented rough endoplasmic reticulum and mitochondria underwent swelling in addition to nucleus with condensed heterochromatin in some hepatocytes (Figs. 14, 16, and 17). Also, active Kupffer cells appeared with many lysosomes (Figs. 15, 16, and 17). Moreover, after treatment for 15 days showed shrinkage of some hepatocytes that lost most of their contents in addition to presence of heterochromation attached to the inner membrane of their nuclear envelope, while in other hepatocytes accumulation of glycogen rosette were appeared (Figs. 18 and 19).

\section{Group III: Adamine-treated mice}

Mice treated with Adamine for 5, 10, and 15 days revealed marked changes in ultrastructure of hepatocytes shown in Figs. 20, 21, 23, and 24 such as mitochondria that lost their cristae. In some hepatocytes, the cisternae of rough endoplasmic reticulum were dilated, while in other cells were fragmented into small stacks. Numerous lysosomes and lipid droplets of varying sizes were observed in the cytoplasm of most hepatocytes. Nucleus appeared with irregular envelope and condensed heterochromatin in some hepatocytes. In addition, active Kupffer cells had many lysosomal bodies and condensed nucleus with irregular envelope was observed in the blood sinusoid (Figs. 22 and 25). Moreover, the cytoplasm of some other hepatocytes showed cytoplasmic vacuolation after treatment for 15 days (Fig. 24).

\section{Group IV: Tamiflu in addition to Adamine-treated mice}

Electron micrographs of liver of mice treated with Tamiflu simultaneously with Adamine for 5, 10, and 15 days 


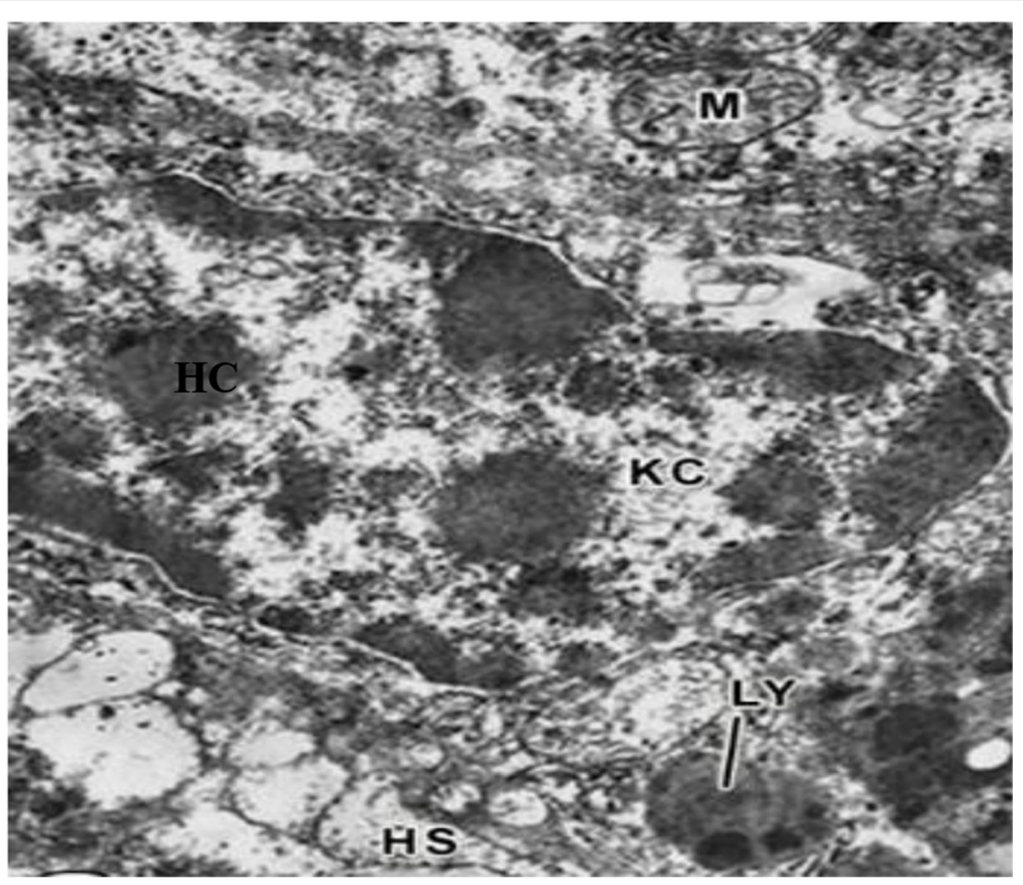

Fig. 13 An electron micrograph of a hepatocyte illustrating the normal manifested phagocytic Kupffer cell (KC) having clumps of

heterochromatin $(\mathrm{HC})$ and facing lumen of the hepatic sinusoid (HS). Lysosomes (LY) which vary in density, shape, and size are also seen in the cytoplasm of Kupffer cell. $(\times 16,000)$

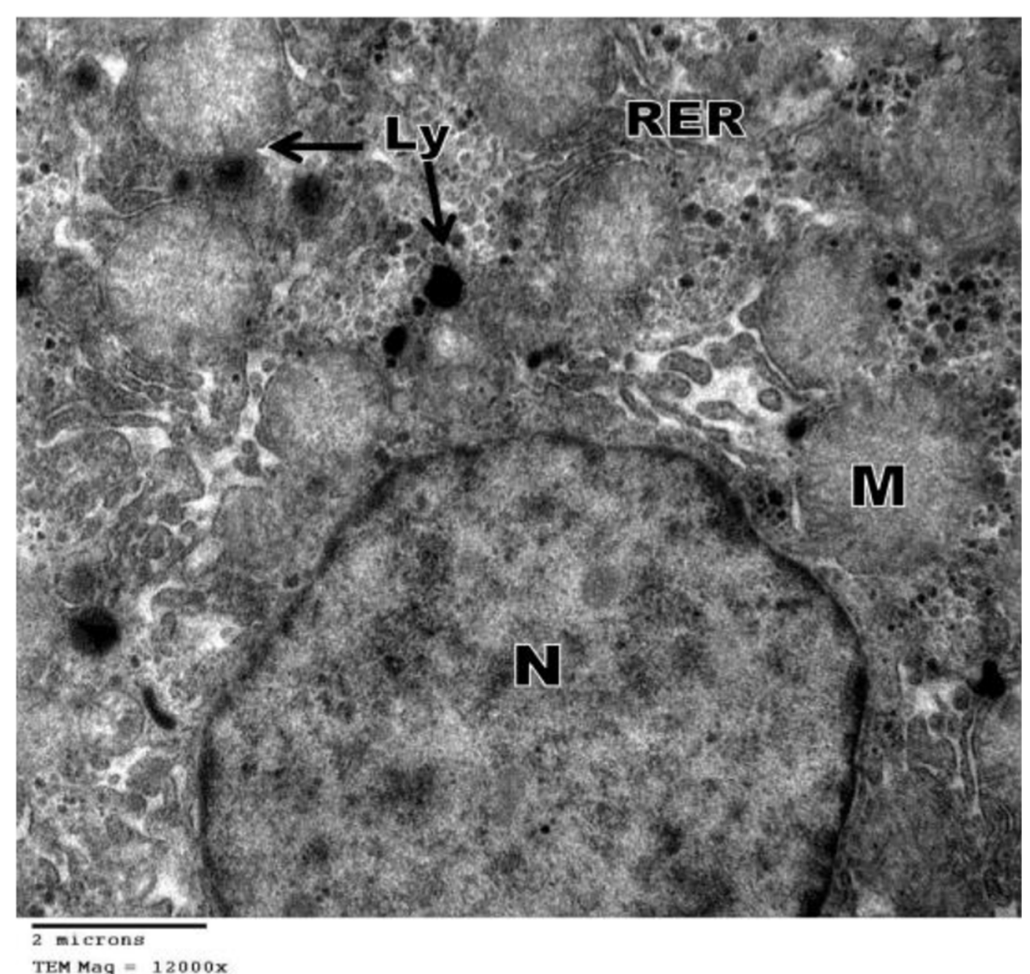

Fig. 14 An electron micrograph of a hepatocyte of treated mouse with Tamiflu (16 mg/kg b.wt.) for 5 days showing short stacks of rough endoplasmic reticulum (RER), swollen mitochondria (M), lysosomes (Ly), and part of the nucleus $(N)$. $(\times 12,000)$ 


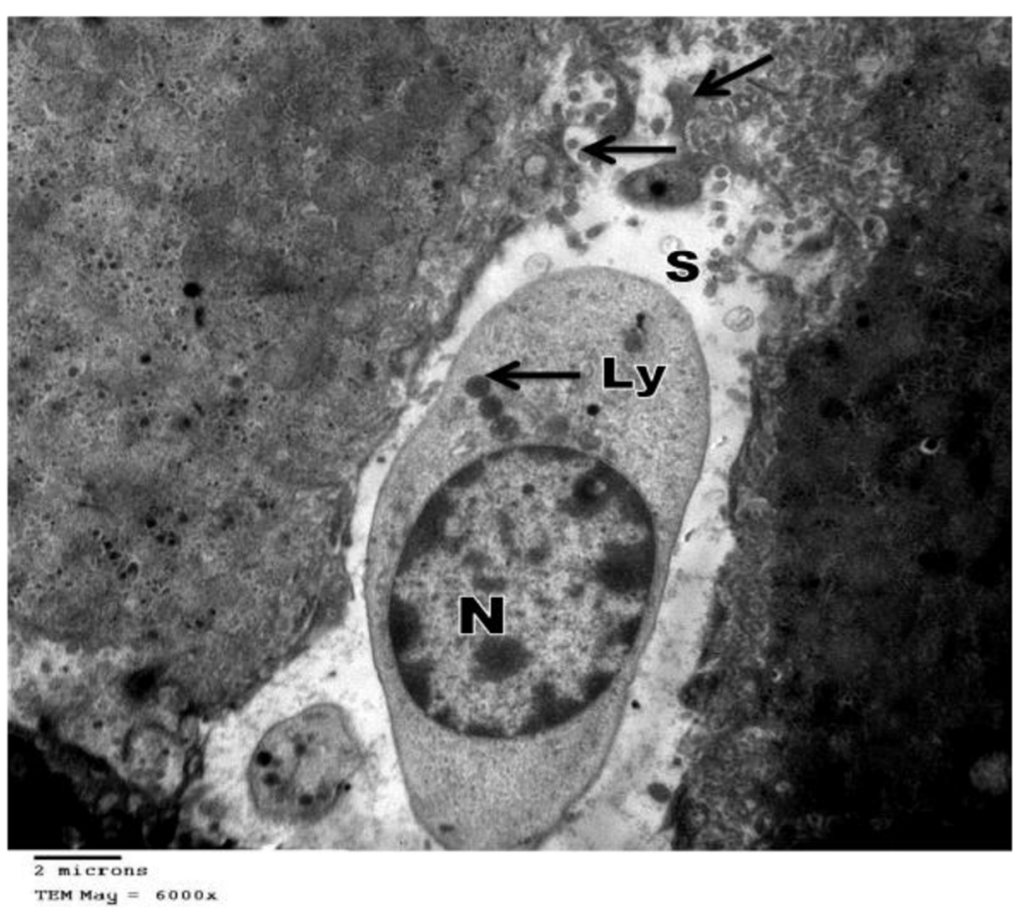

Fig. 15 An electron micrograph of a Kupffer cell of treated mouse with Tamiflu (16 mg/kg b.wt.) for 5 days showing lysosomes (Ly), nucleus (N), dilatation of sinusoid (S), and microvilli (arrows). (× 6000)

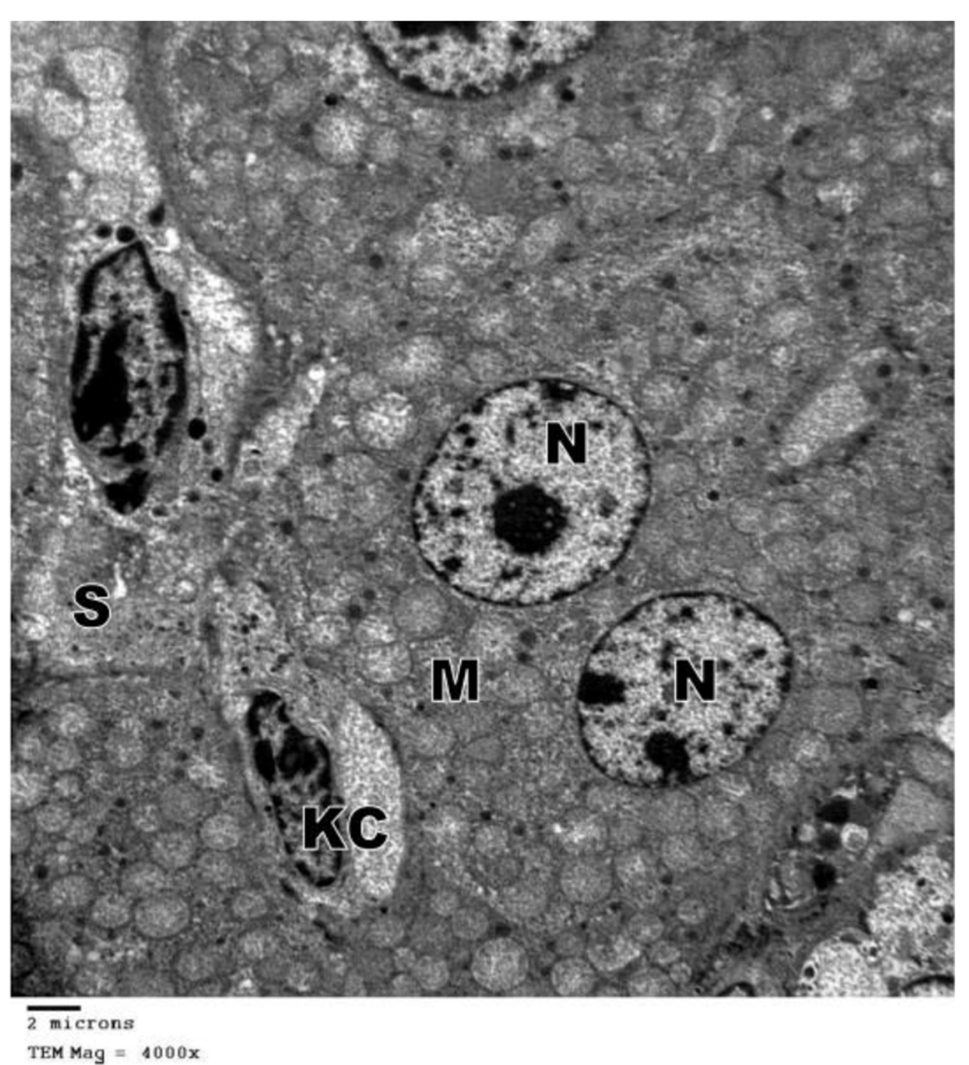

Fig. 16 An electron micrograph of a hepatocyte of treated mouse with Tamiflu (16 mg/kg b.wt.) for 10 days illustrating, binucleated (N) hepatocyte studded with numerous mitochondria (M), sinusoids (S), and Kupffer cell (KC). (× 4000) 


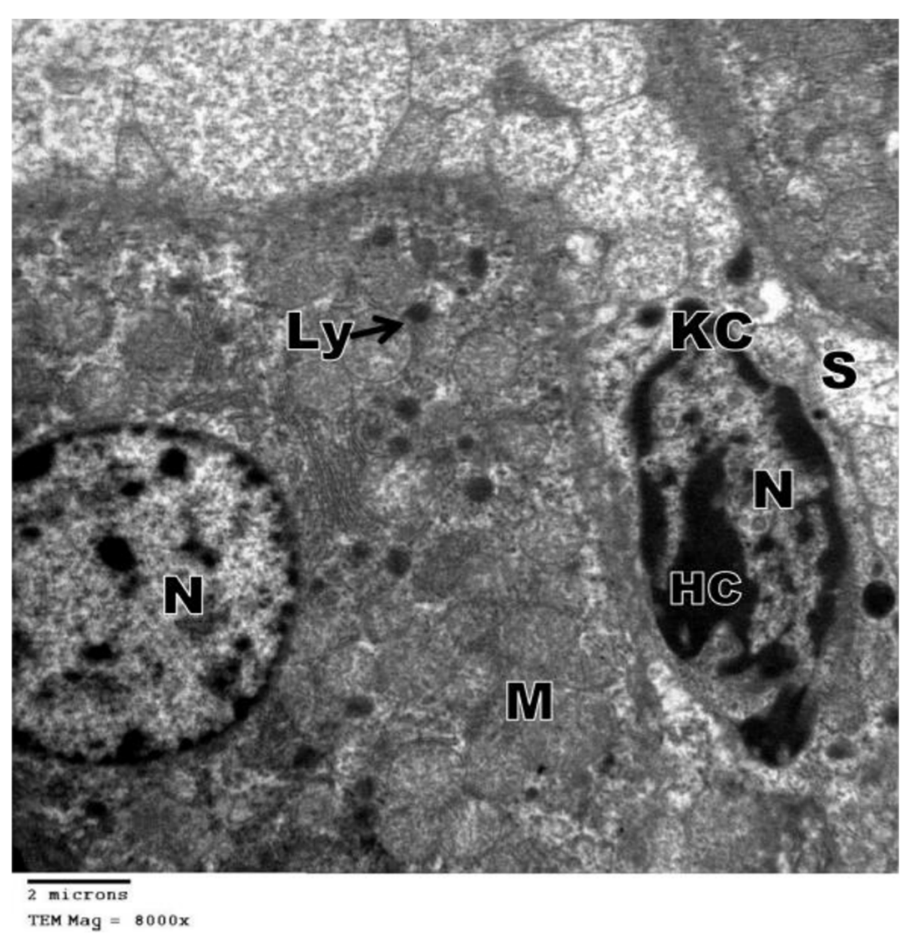

Fig. 17 An electron micrograph of a hepatocyte of treated mouse with Tamiflu (16 mg/kg b.wt.) for 10 days revealing many lysosomes (Ly), mitochondria (M), and Kupffer cell (KC) in sinusoid (S). (× 8000)

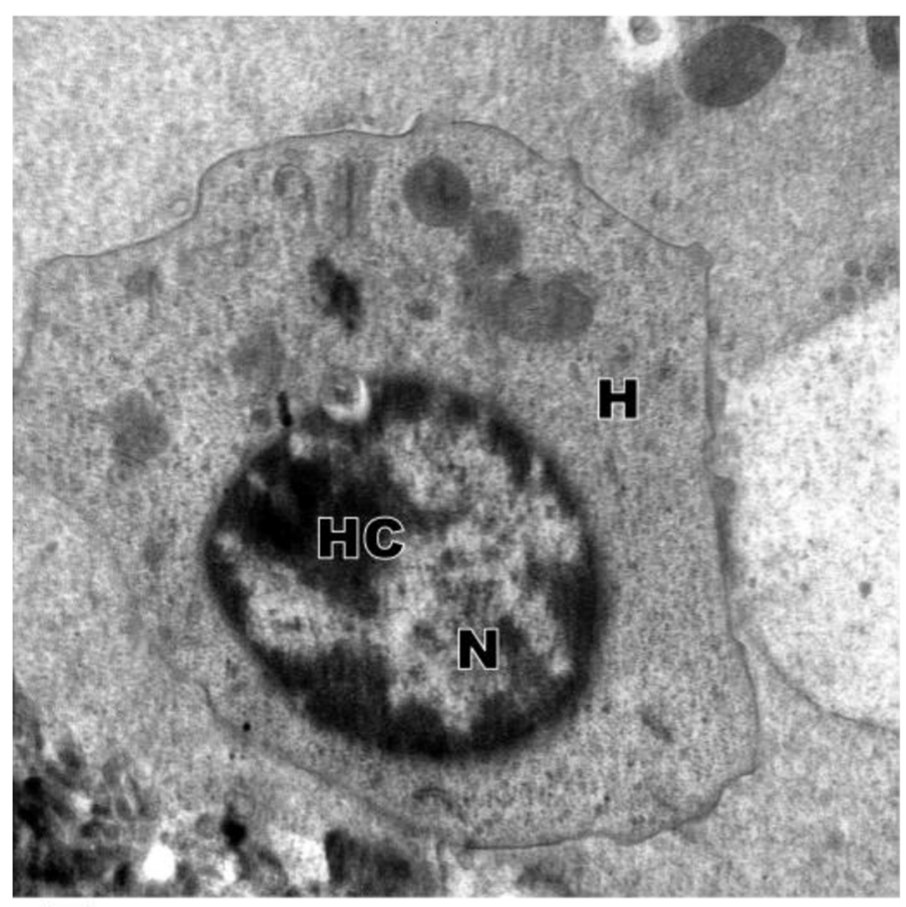

$\overline{500 \mathrm{~nm}}$

TEM Mag = $15000 x$

Fig. 18 An electron micrograph of a hepatocyte of treated mouse with Tamiflu (16 mg/kg b.wt.) for 15 days revealing shrinked hepatocyte (H) lost most of its content and possesses a nucleus $(\mathrm{N})$ with dense heterchromatin $(\mathrm{HC})$ attached to its inner membrane of nuclear envelope. $(\times 15,000)$ 


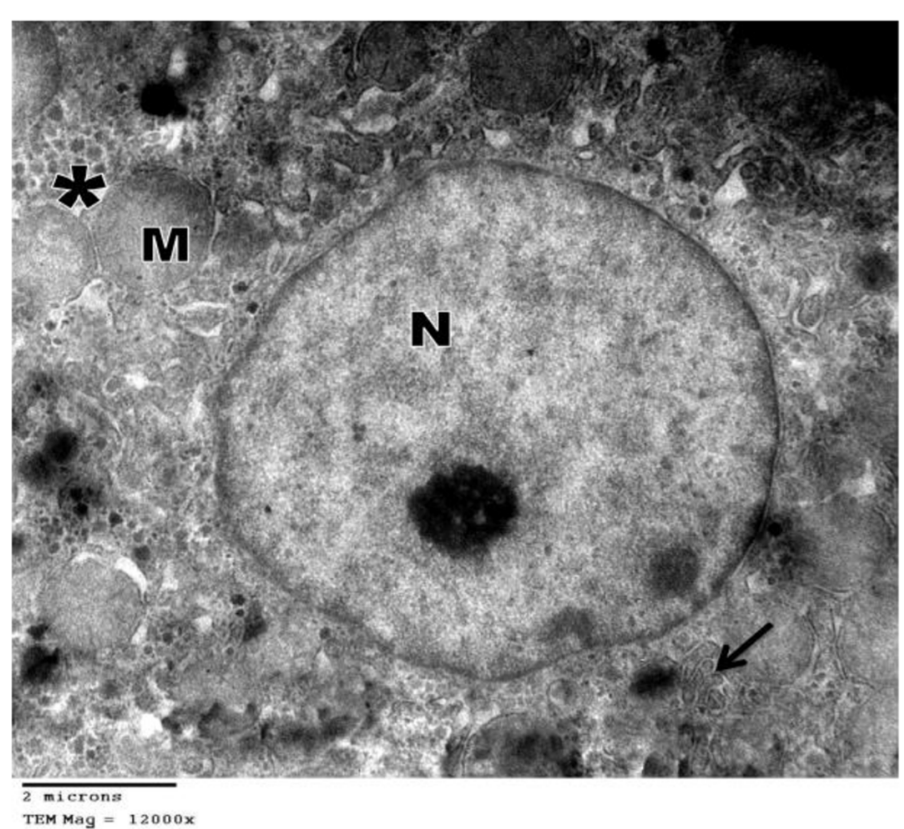

Fig. 19 An electron micrograph of a hepatocyte of treated mouse with Tamiflu (16 mg/kg b.wt.) for 15 days illustrating swollen mitochondria $(\mathrm{M})$, accumulated glycogen rosette $\left(^{*}\right)$, short stacks of dilated rough endoplasmic reticulum (arrow), and nucleus without heterochromatin. $(\times 12,000)$

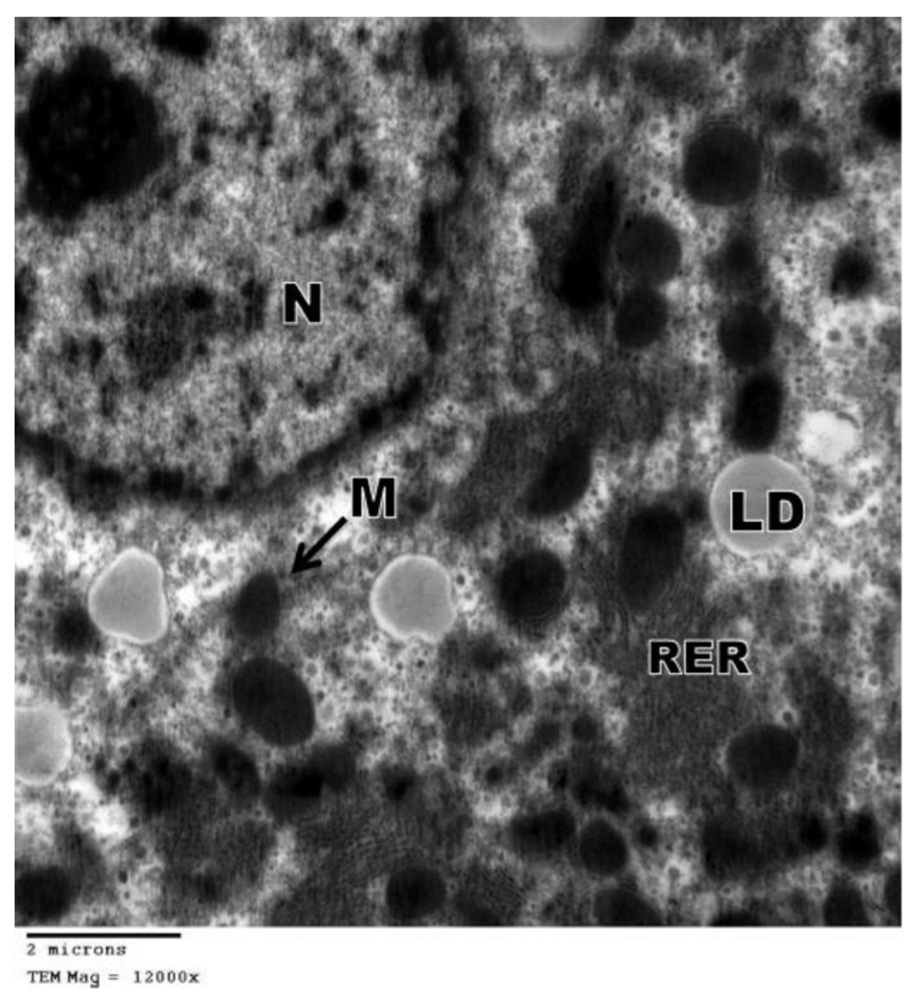

Fig. 20 An electron micrograph of a hepatocyte of treated mouse with Adamine ( $20 \mathrm{mg} / \mathrm{kg}$ b.wt.) for 5 days illustrating the cytoplasm of hepatocyte possesses lipid droplets (LD), rough endoplasmic reticulum (RER), condensed mitochondria (M), and part of nucleus (N) is also seen. $(\times 12,000)$ 


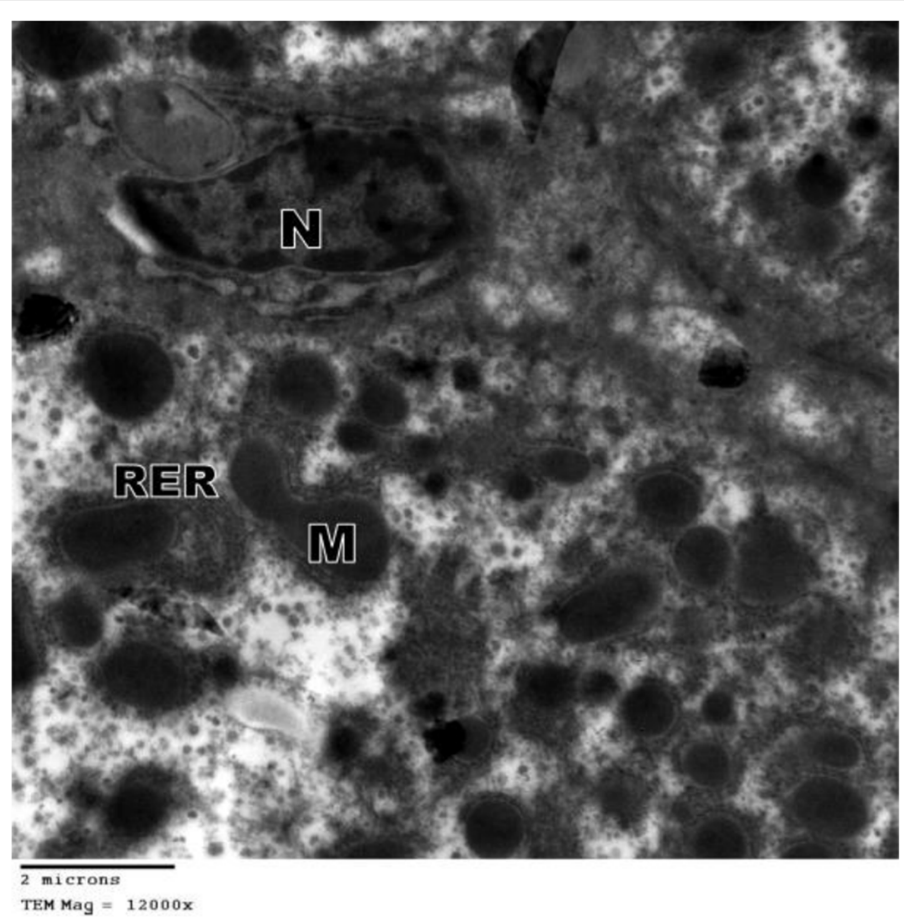

Fig. 21 An electron micrograph of a hepatocyte of treated mouse with Adamine (20 mg/kg b.wt.) for 5 days showing rough endoplasmic reticulum (RER), and condensed mitochondria (M) lost its cristae and pyknotic nucleus $(\mathrm{N})$ of a Kupffer cell. $(\times 12,000)$

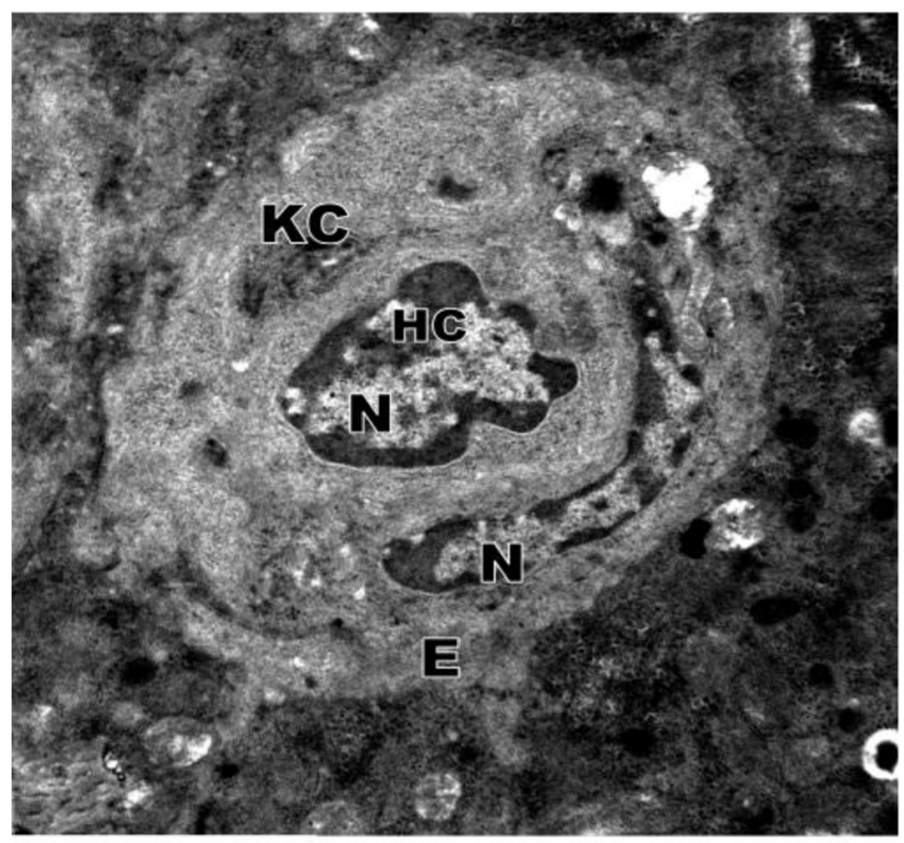

$\overline{2 \text { microns }}$

Fig. 22 An electron micrograph of a hepatocyte of treated mouse with Adamine ( $20 \mathrm{mg} / \mathrm{kg}$ b.wt.) for 10 days illustrating pyknotic nucleus (N) of Kupffer cell (KC) and endothelial cell (E) with elongated nucleus $(\mathrm{N})$ with heterochromatin $(\mathrm{HC})$ attached to inner membrane of nuclear envelope. $(\times 10,000)$ 


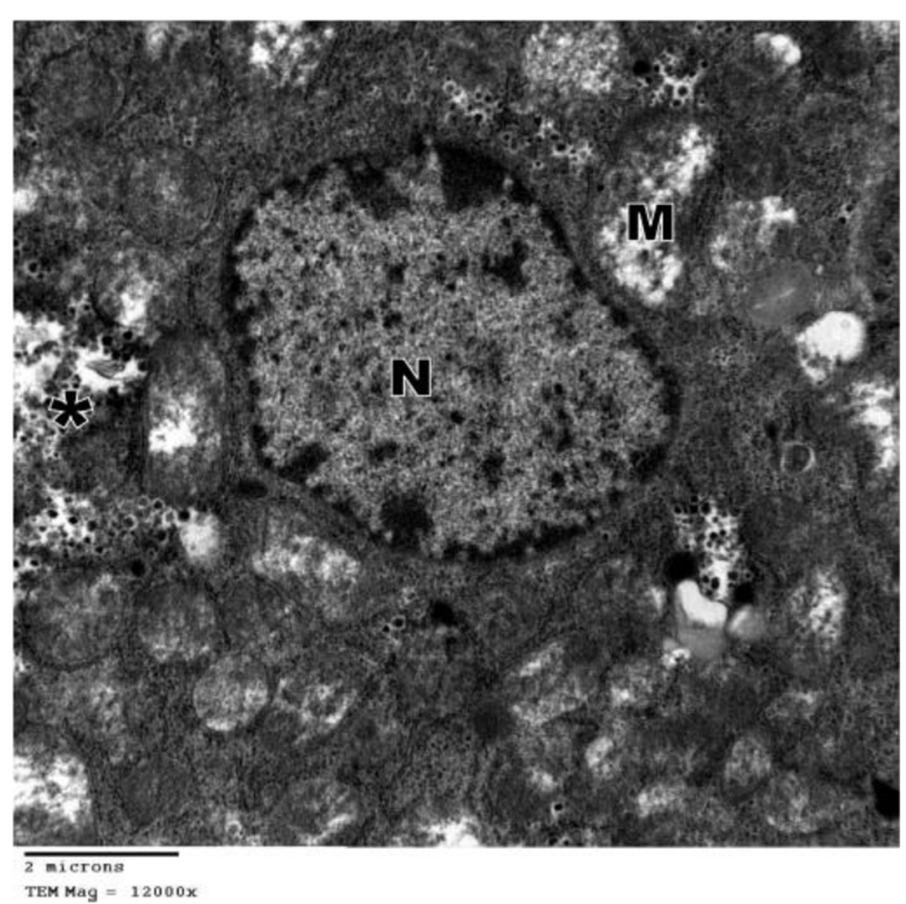

Fig. 23 An electron micrograph of a hepatocyte of treated mouse with Adamine (20 mg/kg b.wt.) for 10 days illustrating swollen mitochondria lost its internal contents $(\mathrm{M})$, glycogen rosette $(*)$, and nucleus $(\mathrm{N}) .(\times 12,000)$

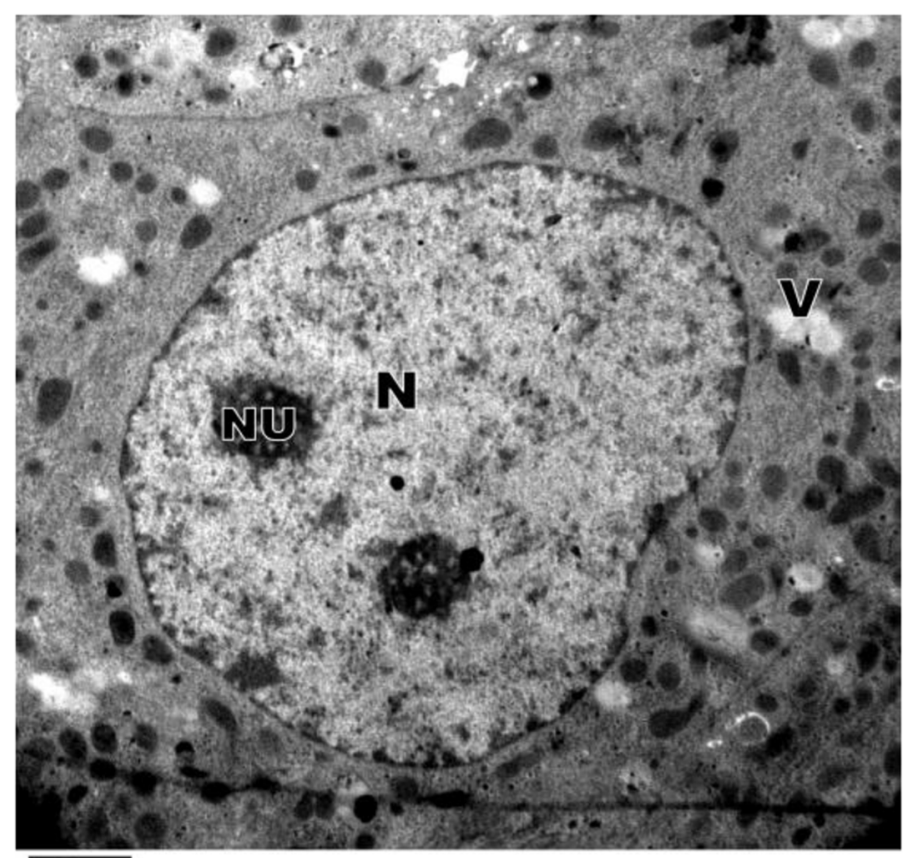

$\overline{2 \text { microns }}$

TEM Mag $=8000 x$

Fig. 24 An electron micrograph of a hepatocyte of treated mouse with Adamine ( $20 \mathrm{mg} / \mathrm{kg}$ b.wt.) for 15 days revealing many vacuoles $(V)$ in cytoplasm and nucleus (N) has two nucleoli (Nu). ( $\times 8000)$ 


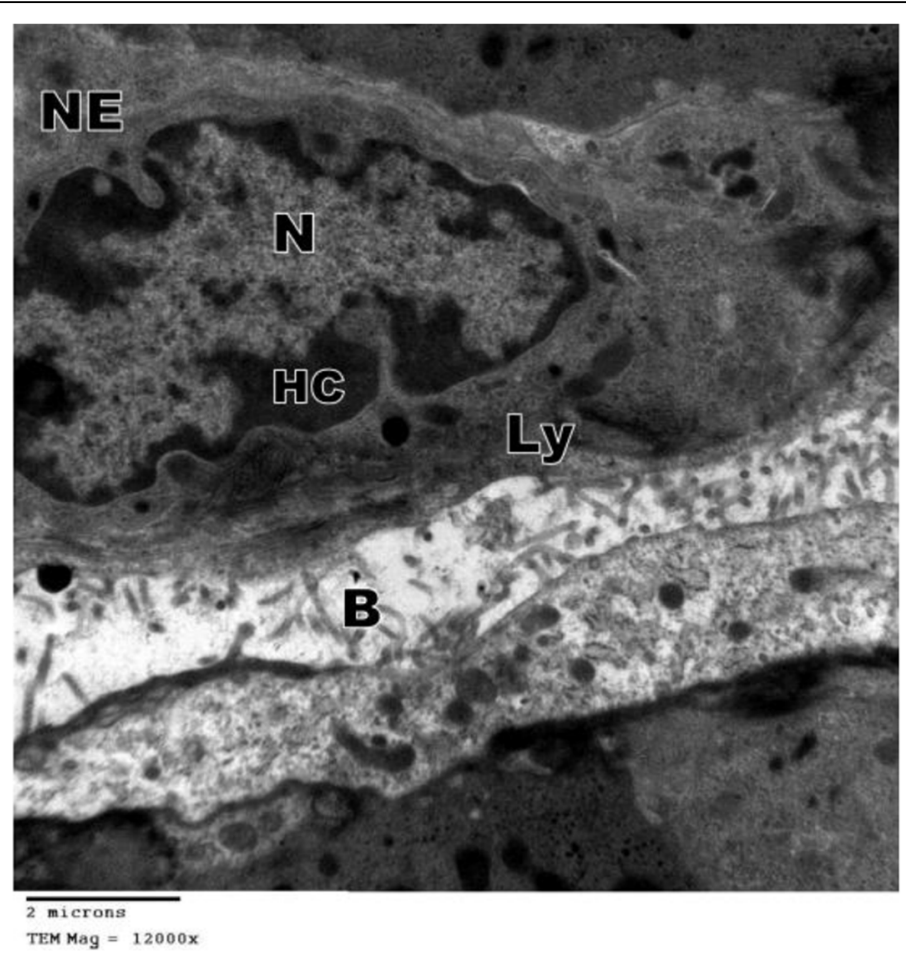

Fig. 25 An electron micrograph of a Kupffer cell of treated mouse with Adamine (20 mg/kg b.wt.) for 15 days showing lysosomes (Ly), nucleus with irregular nuclear envelope (NE), and dense heterochromatin $(\mathrm{HC})$ attached to the inner membrane of nuclear envelope and bile canaliculi (B) is also seen. $(\times 12,000)$

showed severe changes in hepatocytes Figs. 26, 28, and 30 such as disintegration of cytoplasm, swollen mitochondria, presence of many vacuoles in cytoplasm and fragmented rough endoplasmic reticulum. In other hepatocytes, the cytoplasm contained a large number of lipid droplets. Also, nucleus with irregular envelope and condensed heterochromatin appeared in some hepatocytes. In addition, dilated microvilli in sinusoid were observed. There was a hypertrophy of phagocytic Kupffer cells which distinctly activated as symptomized by the presence of many lysosomal granules in their cytoplasm and extension of filopodia from their plasma membrane (Figs. 26, 27, 28, 29, 30 and 31).

\section{Discussion}

The observations obtained from the present histopathological study illustrated that oral administration of Tamiflu and Adamine to male mice have induced mild, moderate, and severe lesions in liver tissue. The pathological responses of the liver tissues to Tamiflu and Adamine were time-dependent.

Remarkable abundance of the infiltrative inflammatory cells were seen in addition to marked congestion and dilatation of the central and portal veins, which were associated with erosion in their endothelial linings and the accumulation of stagnant blood cells in their lumens.
The present study illustrated marked consequences in the hepatic vasculatures including congestion, dilatation of the hepatic central veins and surrounding sinusoids, besides erosion of their endothelial lining cells and the activation of the phagocytic Kupffer cells in the liver of mice treated with Tamiflu and Adamine. These results agree with results of Arcidi Jr et al. [1] and Dai et al. [4] who found that congestion of the liver is reflected by sinusoidal dilation, congestion, and hepatocyte atrophy. Elevated hepatic venous pressures may precipitate extravasation of red blood cells into the space of Disse. In addition to the extent of necrosis, inflammation, and dilation has been correlated with right atrial and hepatic pressures [21] although ischemia may lead to findings of necrosis as well. Chronic congestion leads to perivenular fibrosis and, eventually, cirrhosis. This finding is in accordance with those observed by $[8,9]$ who reported such alteration in the hepatocytes of the treated mice post monosodium glutamate application and post depakine and epanutin on other treated mice.

The results of present work are in agreement with those obtained by Ju et al. [17], who mentioned that Kupffer cells can be a protective from drug-induced liver injury and Kaji et al. [18], who reported two patients with hepatoma associated with liver cirrhosis after treatment with the neuraminidase inhibitors zanamivir and oseltamivir administered as a prophylactic agent. 


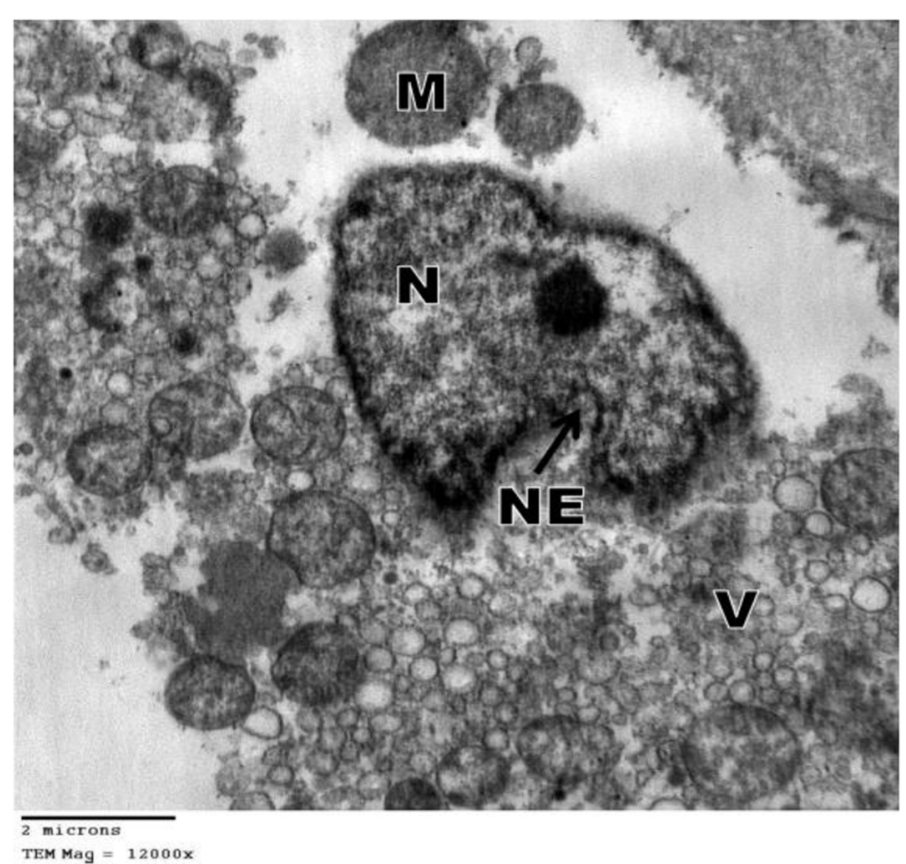

Fig. 26 An electron micrograph of a hepatocyte of treated mouse with Tamiflu (16 mg/kg b.wt.) in addition to Adamine (20 mg/kg b.wt.) for 5 days revealing desintigration of cytoplasm, swollen mitochondria $(M)$, vacuoles $(\mathrm{V})$, and the nucleus $(\mathrm{N})$ with irregular nuclear envelope (NE). $(\times 12,000)$

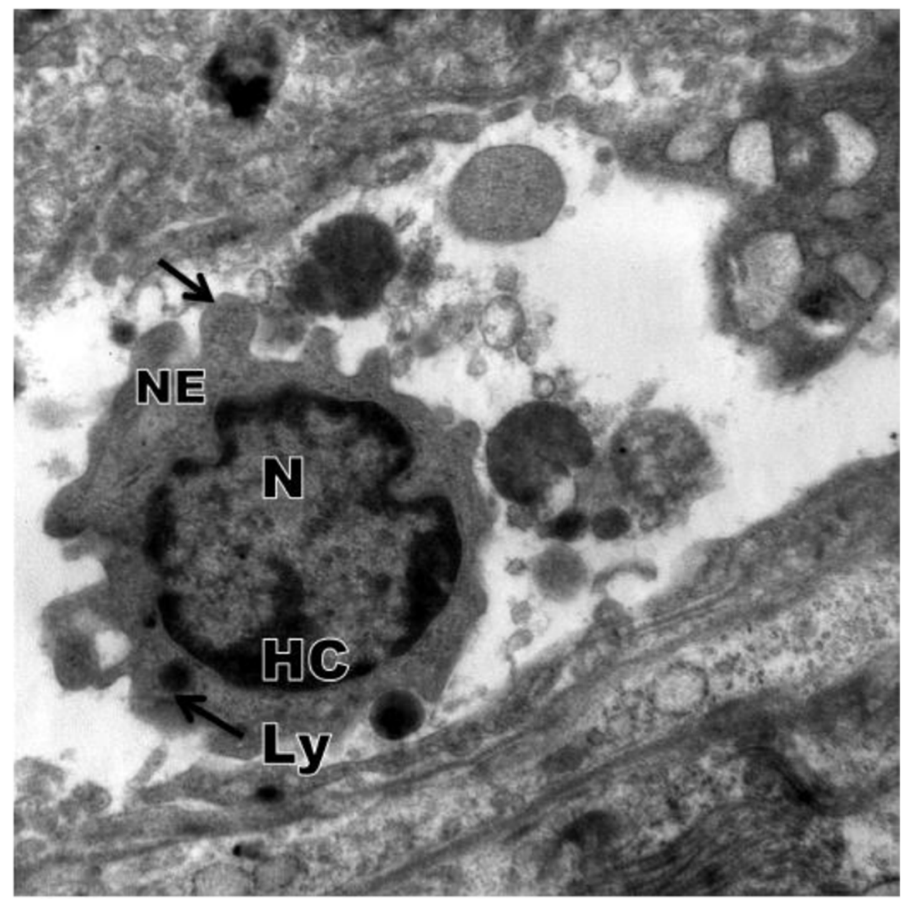

\section{$\overline{500 \mathrm{~nm}}$}

TEM Mag $=15000 x$

Fig. 27 An electron micrograph of a Kupffer cell of treated mouse with Tamiflu ( $16 \mathrm{mg} / \mathrm{kg}$ b.wt.) in addition to Adamine ( $20 \mathrm{mg} / \mathrm{kg}$ b.wt.) for 5 days revealing fillopodia in cell membrane of Kupffer cell (arrow), lysosomes (Ly), and nucleus (N) with irregular nuclear envelope (NE) had heterochromatin $(\mathrm{HC})$ attached to inner membrane of the nuclear envelope. $(\times 15,000)$ 


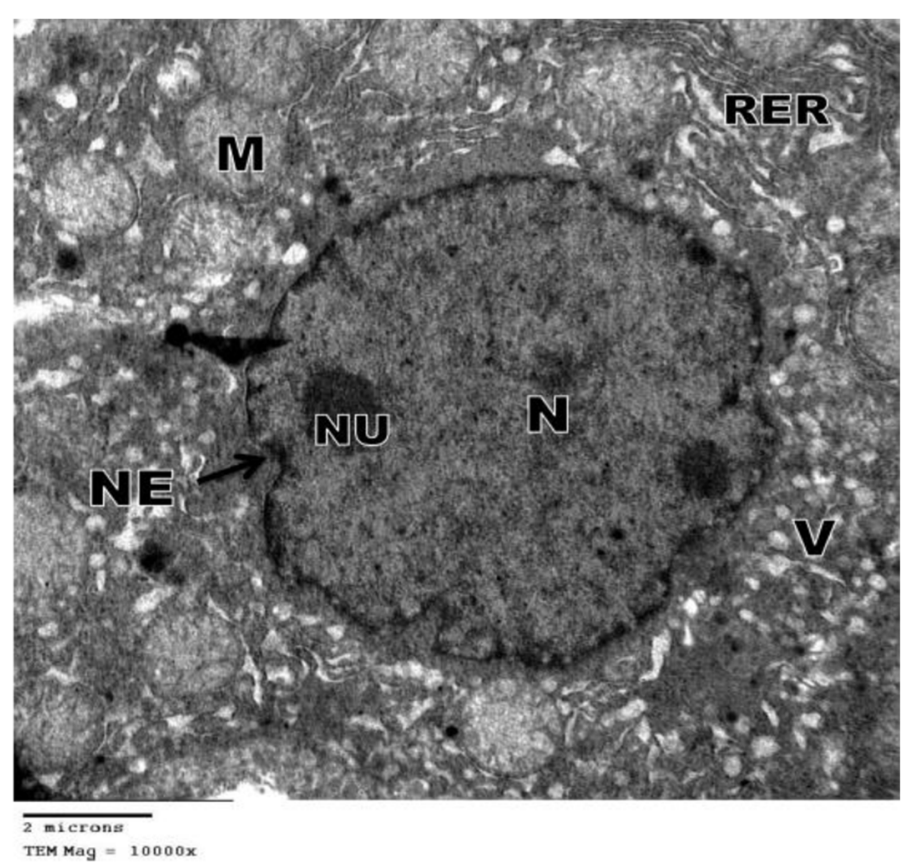

Fig. 28 An electron micrograph of a hepatocyte of treated mouse with Tamiflu (16 mg/kg b.wt.) in addition to Adamine (20 mg/kg b.wt.) for 10 days revealing swollen mitochondria (M), rough endoplasmic reticulum (RER), vacuoles $(\mathrm{V}$ ), and nucleus (N) with irregular envelope (NE) and two nucleoli $(\mathrm{Nu}) .(\times 10,000)$

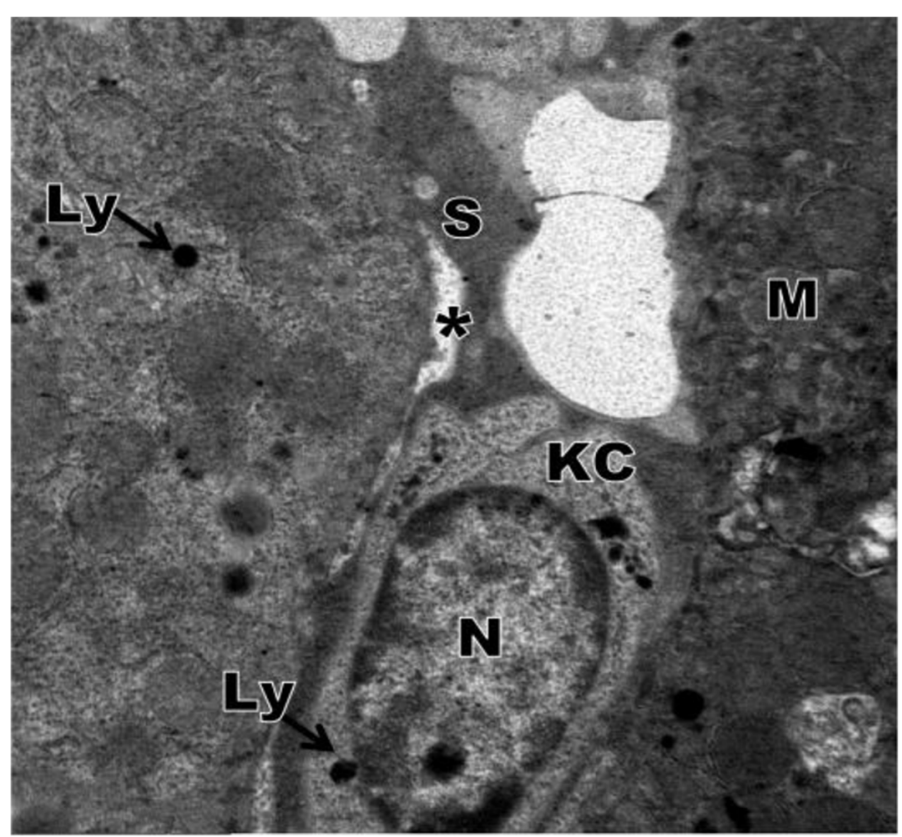

Fig. 29 An electron micrograph of a hepatocyte of the liver of treated mouse with Tamiflu (16 mg/kg b.wt.) in addition to Adamine (20 mg/kg b.wt.) for 10 days revealing lysosomes (Ly), swollen mitochondria (M) in hepatocyte, and sinusoid (S) had Kupffer cell (KC) containing lysosomes $(\mathrm{Ly})$ and nucleus $(\mathrm{N})$ in addition to space of Diss $\left(^{*}\right) .(\times 10,000)$ 


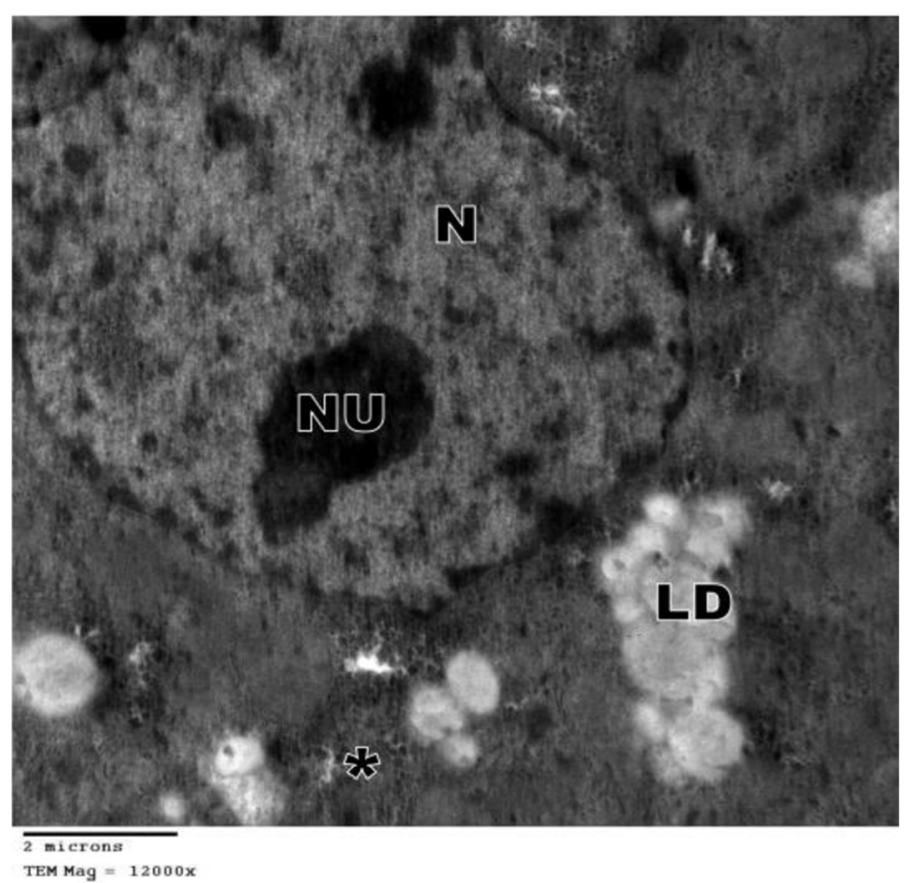

Fig. 30 An electron micrograph of a hepatocyte of treated mouse with Tamiflu (16 mg/kg b.wt.) in addition to Adamine (20 mg/kg b.wt.) for 15 days revealing lipid droplets $(\mathrm{LD})$, glycogen rosette $(*)$, and nucleus $(\mathrm{N}) .(\times 12,000)$

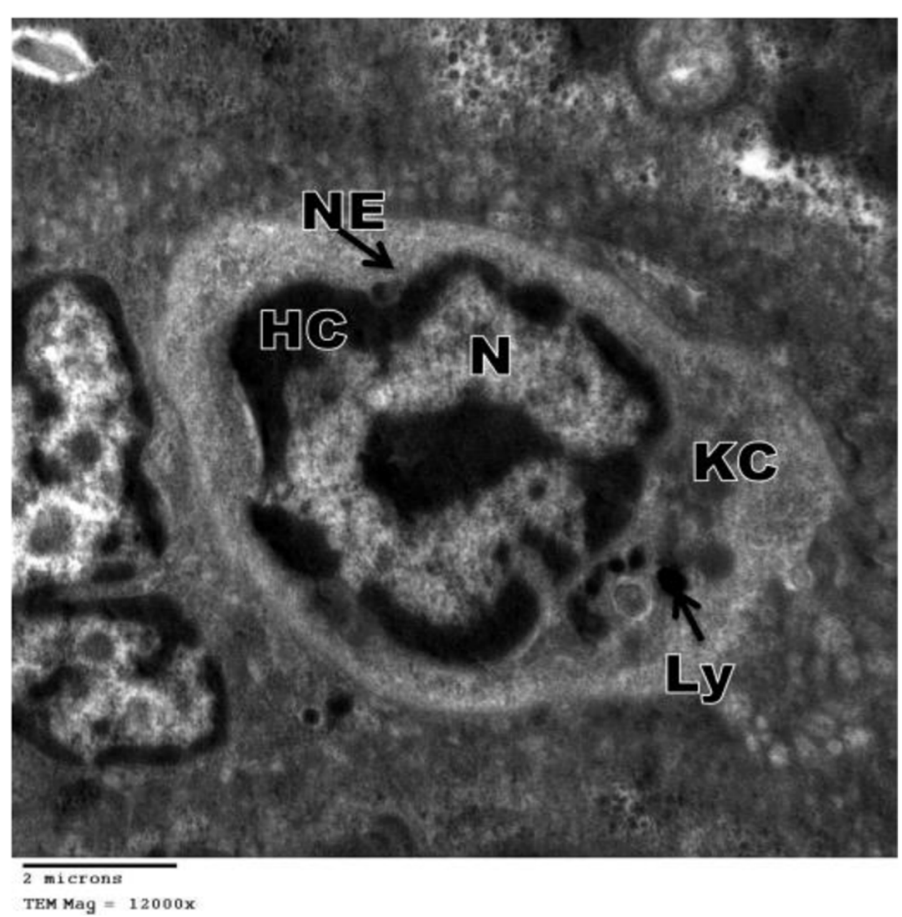

Fig. 31 An electron micrograph of a Kupffer cell of treated mouse with Tamiflu (16 mg/kg b.wt.) in addition to Adamine (20 mg/kg b.wt.) for 15 days revealing lysosomes (Ly) and nucleus (N) with irregular nuclear envelope (NE) with heterochromatin attached to the inner membrane (HC) of the nuclear envelope. $(\times 12,000)$ 
Also present results agree with the study which obtained by Gao et al. [11], who suggested that oseltamivir may inhibit both viral entry and release but may also enhance apoptosis of infected cells and interfere with natural killer cell (NK) function during influenza infection.

At the ultrastructural level, the alterations are timedependent and involved the mitochondria, endoplasmic reticulum, lysosomes, nucleus, and Kupffer cells. The present results have displayed picture for the mitochondria differ from the control ones, being affected by the Tamiflu and Adamine administration. The mitochondria became swollen and lost their cristae, progressively damaged, and their debris were thrown into their heavily electron dense matrices.

Mitochondria are essential double-membrane subcellular organelles. Their function is to support aerobic respiration and production of ATP by oxidative phosphorylation [14]. In addition to oxidative phosphorylation, the mitochondria control cytosolic calcium concentration [25] and the major source of endogenous reactive oxygen species [29]. Also, mitochondria act as gate keepers of cell life and cell death regulate both apoptotic and necrotic cell death, and so its disturbances involving these pathways may trigger cell death [19].

The results of the present study are in agreement with the results obtained by Giovanni et al. [12] in their study on isolated mouse liver mitochondria demonstrated that amantadine induces hyperpolarization of the membrane potential. Moreover, amantadine treatment increased the calcium threshold required to trigger mitochondrial permeability transition opening.

In the present study, the rough endoplasmic reticulum has undergone marked fragmentation into small stacks. Also, the smooth endoplasmic reticulum has undergone dilatation.

The results of the present study agree with the results observed by Forchap et al. [10], who reported that in longer term experiments, both drugs (amantadine and prazosin) paradoxically increase the cytotoxicity of all three currently licensed tyrosine kinase inhibitors, imatinib, nilotinib, and dasatinib. This effect is due to release of intracellular calcium from the endoplasmic reticulum, with changes in mitochondrial calcium and alterations in mitochondrial membrane permeability, resulting in caspase-mediated apoptosis. These results indicate that calcium release from the ER, here induced by amantadine or prazosin, may prime BCR-ABLpositive cells to tyrosine kinase inhibitors-induced apoptosis.

The observations in the present study have found an increase in number of lysosomes, these observation previously described by Phillips et al. [24] to be involved in the metabolism or storage of a number of drugs and any lysosomal changes occur could be due to focal cytoplasmic degradation, a process in which lysosomes are associated with digestion of damaged portions of the hepatic cytoplasm.

The present study showed an increase of lysosomes in hepatocytes. These observations are in accordance with those reported by Sakr [28] who illustrated distinct change in lysosomes of the hepatocytes of mouse treated with tamoxifen.

Many hepatocytes showed nuclear changes include erosion and rupture of the nuclear envelope and more electron dense chromatin attached to inner membrane of the nuclear envelope. Also, pyknotic nuclei were observed in the present work.

Hypertrophied Kupffer cells were common ultrastructural finding in adverse drug and toxic reactions of the liver as clearly designated in the present work and symptomized by the presence of many lysosomal granules in their cytoplasm and extension of filopodia. The phagocytic activity of Kupffer cells could be a result of hypertrophy of the rough endoplasmic reticulum and an increase in the number and size of lysosomes in Kupffer cells. Kupffer cells are usually associated with extensive hepatocellular injury 'necrosis' [13]. This finding is in accordance with those observed by Sakr [28] who reported such alteration of Kupffer cells in the hepatocytes of the treated mice post tamoxifen application.

On the other hand, these results contradict with the findings obtained by Nassim et al. [22], who reported that Amantadine monotherapy has no impacts upon liver histology.

\section{Conclusion}

In conclusion, the results of the present study illustrated that Tamiflu and Adamine separately or simultaneously caused histopathological and ultrastructural alterations in the liver of male albino mice.

\section{Abbreviations \\ B: Bile canaliculi; S: Blood sinusoids; C: Central vein; V: Cytoplasmic vacuolation; E: Endothelial cell; EC: Euchromatin; HPV: Hepatic portal vein; HS: Hepatic sinusoid; H: Hepatocyte; HC: Heterochromatin; INF: Inflammatory cells; KC: Kupffer cells; LD: Lipid droplets; LY: Lysosomes; M: Mitochondria; NE: Nuclear envelope; NU: Nucleolus; N: Nucleus; RER: Rough endoplasmic reticulum}

\section{Acknowledgements} Not applicable.

\section{Authors' contributions}

$\mathrm{HO}$ performed the histological and ultrastructural examination of the liver, and was a major contributor in writing the manuscript. SS helped in the interpretation of the results and editing the manuscript. All authors read and approved the final manuscript. 


\section{Availability of data and materials}

All the data supporting the findings of this study are available within the article.

\section{Declarations}

\section{Ethics approval and consent to participate}

Animal care and use protocols were carried out according to animal care guidelines approved by the authorities of Ain Shams University. Committee's reference number is not applicable.

\section{Consent for publication}

Not applicable.

\section{Competing interests}

The authors declare that they have no competing interests.

\section{Received: 19 February 2021 Accepted: 18 May 2021}

Published online: 26 June 2021

\section{References}

1. Arcidi JM Jr, Moore GW, Hutchins GM (1981) Hepatic morphology in cardiac dysfunction: a clinicopathologic study of 1000 subjects at autopsy. Am J Pathol 104:159-166 PMID: 6455066; PMCID: PMC1903755

2. Bancroft JD, Gamble M (2002) Theory and practice of histological techniques, 5th edn. Churchill Livingstone, London, New York, Philadelphia, pp 109-136 PMCID: PMC476681

3. Burger RA, Billingsley JL, Huffman JH, Bailey KW, Kim CU, Sidwell RW (2000) Immunological effects of the orally administered neuraminidase inhibitor oseltamivir in influenza virus-infected and uninfected mice. Immunopharmacology 47:45-52. https://doi.org/10.1016/s0162-3109(99)001 84-8 PMID: 10708809

4. Dai DF, Swanson PE, Krieger EV, Liou IW, Carithers RL, Yeh MM (2014) Congestive hepatic fibrosis score: a novel histologic assessment of clinical severity. Mod Pathol 27:1552-1558. https://doi.org/10.1038/modpathol.2014. 79 PMID: 24925051

5. Dogan G, Karaca O (2020) N-methyl-D-aspartate receptor antagonists may ameliorate spinal cord injury by inhibiting oxidative stress: an experimenta study in rats. Turk Neurosurg 30:60-68. https://doi.org/10.5137/1019-5149. JTN.26801-19.3 PMID: 32091112

6. Dutkowski R, Thakrar B, Froehlich E, Suter P, Oo C, Ward P (2003) Safety and pharmacology of oseltamivir in clinical use. Drug Saf 26:787-801. https://doi. org/10.2165/00002018-200326110-00004 PMID: 12908848

7. Dykstra MJ, Mann PC, Eiwell MR, Ching SV (2002) Suggested standard operating procedure (SOPs) for the preparation electron microscopy samples for toxicology/pathology studies in a GLP environment. Toxicol Pathol 30:735-743 pISSN: 2356-9174, elSSN: 2356-9182

8. El-Alfy NZ, Mahmoud FM, Eissa MI, Emam AA (2020a) Role of propolis against toxic effects of monosodium glutamate on histology and expression lipid metabolism genes of mice liver. Indian J Public Health Res Dev 11:867-873. https://doi.org/10.37506/ijphrd.v11i5.9548

9. El-Alfy NZ, Alqosaibi Al, Mahmoud FM, Abdullah AM (2020b) Evaluation of hepatotoxicity of two famous antiepileptic drugs Depakine ${ }^{\oplus}$ and / or Epanutin ${ }^{\oplus}$ in male albino mice mus musculus: integrated biochemical and histological studies. Indian J Public Health Res Dev 11:235-241. https://doi. org/10.37506/ijphrd.v11i11.11378

10. Forchap SL, Pirmohamed M, Clark RE (2012) Release of intracellular calcium primes chronic myeloid leukaemia cells for tyrosine kinase inhibitor-induced apoptosis. Leukemia 26:490-498. https://doi.org/10.1038/leu.2011.231 PMID: 21886172

11. Gao R, Du N, Liu D, Li Z, Zhu Y, Shu Y (2013) Oseltamivir inhibits both viral entry and release but enhances apoptosis of cells infected with influenza $A$ H1N1. Biochem Biophys Res Commun 431:788-795. https://doi.org/10.1016/ j.bbrc.2013.01.019 PMID: 23333739

12. Giovanni Q, Rosella S, Maria R, Francesca A, Darius M, Nazzareno C, Claudia P (2014) Protective role of amantadine in mitochondrial dysfunction and oxidative stress mediated by hepatitis C virus protein expression. Biochem Pharmacol 89: 545-556. https://doi.org/10.1016/j.bcp.2014.03.018 PMID: 24726442

13. Haschek WM, Rousseaux CG (1991) Toxicologic pathology. Academic, London and New York Hardcover ISBN: 9780124157590
14. Hatefi Y (1985) The mitochondrial electron transport and oxidative phosphorylation system. Annu Rev Biochem 54:1015-1069. https://doi.org/1 0.1146/annurev.bi.54.070185.005055 PMID: 2862839

15. He CH, Liu CY, Lin GY, Peng Q, Liao JY, Lin JH, Zhang T, Zheng XF, Lin CX, Wang SJ, Chen RS, Deng L, Chen YM (2017) Efficacy and safety of oseltamivir in children with suspected influenza: a multicenter randomized open-label trial. Zhonghua Er Ke Za Zhi 55:462-467. https://doi.org/10.3760/ cma.j.issn.0578-1310.2017.06.014 PMID: 28592016

16. Ison (2012) Clinical use of approved influenza antivirals: therapy and prophylaxis. Influenza Other Respir Viruses 7:7-13. https://doi.org/10.1111/ irv.12046

17. Ju C, Reilly TP, Bourdi M, Radonovich MF, Brady JN, George JW, Pohl LR (2002) Protective role of Kupffer cells in acetaminophen-induced hepatic injury in mice. Chem Res Toxicol 15:1504-1513. https://doi.org/10.1021/tx02 55976 PMID: 12482232

18. Kaji M, Fukuda T, Tanaka M, Aizawa H (2005) A side effect of neuraminidase inhibitor in a patient with liver cirrhosis. J Infect Chemother 11:41-43. https://doi.org/10.1007/s10156-004-0358-7 PMID: 15729487

19. Michael R, Duchen, Gyorgy S (2010) Roles of mitochondria in human disease. Biochem Soc 47:115-137. https://doi.org/10.1042/bse0470115 PMID: 20533904

20. Morrison D, Roy S, Rayner C, Amer A, Howard D, Smith JR, Evans TG (2007) A randomized, crossover study to evaluate the pharmacokinetics of amantadine and oseltamivir administered alone and in combination. PLoS One 2:1305. https://doi.org/10.1371/journal.pone.0001305 PMID: 18074029 PMCID: PMC2110886

21. Myers RP, Cerini R, Sayegh R, Moreau R, Degott C, Lebrec D, Lee SS (2003) Cardiac hepatopathy: clinical, hemodynamic, and histologic characteristics and correlations. Hepatology 37:393-400. https://doi.org/10.1053/jhep.2003. 50062 PMID: 12540790

22. Nassim K, Lionel R, Karine S, David R, Dominique D, Jacques I (2004) Amantadine therapy in renal transplant patients with hepatitis C virus infection. J Clin Virol 30: 110-114. https://doi.org/10.1034/j.1600-6143.2003.00057.x

23. Paget GE, Barnes JM (1964) Toxicity tests. In: Laurence DR, Bacharach AL (eds) Evaluation of drug activities: pharmacometrics, vol I (part:1). Academic, London and New York, pp 135-166. https://doi.org/10.1016/B978-1-4832-2 845-7.50012-8

24. Phillips MJ, Poucell S, Patterson J, Valencia P (1987) The liver: an atlas and text of ultrastructural pathology. Raven Press, New York, pp 159-238

25. Pozzan T, Magalhaes P, Rizzuto R (2000) The comeback of mitochondria to calcium signaling. Cell Calcium 28:279-283. https://doi.org/10.1054/ceca.2 000.0166

26. Reynolds ES (1963) The use of lead citrate at high $\mathrm{pH}$ as an electron opaque stain in electron microscopy. J Cell Biol 17:208-212. https://doi. org/10.1083/jcb.17.1.208 PMID: 13986422 PMCID: PMC2106263

27. Risebrough NA, Bowles SK, Simor AE, McGeer A, Oh PI (2005) Economic evaluation of oseltamivir phosphate for postexposure prophylaxis of influenza in long-term care facilities. J Am Geriatr Soc 53:444-451. https:// doi.org/10.1111/j.1532-5415.2005.53162.x PMID: 15743287

28. Sakr (2007) Influence of tamoxifen on the liver of albino mice and the possible protecteive role of vitamin C. Egypt J Zool 49:233-252 www. egyzolsoc.com

29. Starkov AA (2008) The role of mitochondria in reactive oxygen species metabolism and signaling. Ann N Y Acad Sci 1147:37-52. https://doi.org/1 0.1196/annals.1427.015 PMID: 19076429 PMCID: PMC2869479

30. Sweeny DJ, Lynch G, Bidgood AM, Lew W, Wang KY, Cundy KC (2000) Metabolism of the influenza neuraminidase inhibitor prodrug oseltamivir in the rat. Drug Metab Dispos 7:737-741 PMID: 10859145

\section{Publisher's Note}

Springer Nature remains neutral with regard to jurisdictional claims in published maps and institutional affiliations. 